\title{
La noción de colocación en las partes introductorias de algunos diccionarios monolingües del español ${ }^{*}$
}

\author{
ANA MARÍA RUIZ MARTÍNEZ \\ Universidad de Alcalá
}

\section{INTRODUCCIÓN}

Desde hace ya varias décadas, en el ámbito de la lingüística hispánica el fenómeno de la colocación se ha venido prestando a diferentes interpretaciones y su análisis se ha emprendido desde diversos puntos de vista, de ahí que Alonso Ramos (1994-1995: 9) haya precisado que la definición del concepto se impone si se quiere acometer convenientemente la descripción de las colocaciones en los diccionarios. Esta afirmación, no obstante, no quiere decir que la lexicografía española haya excluido las colocaciones de sus obras, pero sí puede interpretarse como un lamento ante la asistematicidad e inadecuación con la que los diccionarios han tratado esta cuestión en su microestructura. A ello se une también la mínima voluntad que muestran estas obras por recoger en sus páginas preliminares las colocaciones, pues las referencias al concepto no suelen ser explícitas y muchas veces sólo son deducibles de una manera indirecta. A tenor de las escasas investigaciones que se han emprendido hasta el momento, ${ }^{1}$ nos proponemos en este artículo examinar con detalle todas aquellas menciones que, de una manera directa o indirecta, las partes introductorias de tres tipos específicos de diccionarios de la lengua española reservan al término colocación y al concepto que éste recoge. ${ }^{2}$ Con nuestro análisis nos proponemos tres objetivos principales:

1. Determinar si los diccionarios muestran interés o no por el concepto de colocación en sus páginas introductorias.

2. Identificar todas aquellas denominaciones bajo las que puede recogerse el concepto de colocación.

3. Esclarecer si las obras examinadas diferencian el concepto de colocación de otros conceptos afines vinculados con otras clases de combinaciones léxicas.

De manera complementaria, nos ocuparemos también de analizar de qué forma toda la información preliminar presentada en torno al concepto de colocación aparece recogida después en la microestructura de cada diccionario.

\footnotetext{
${ }^{*}$ Este artículo se enmarca en el proyecto Fraseografia teórica y aplicada. Bases para la elaboración de un diccionario de locuciones (UAH GC2007-004), financiado por la Universidad de Alcalá.

${ }^{1}$ En Bargalló Escrivá y otros (1997-1998) se ha analizado qué información contienen las páginas preliminares y los apéndices complementarios de algunos diccionarios generales y didácticos de la lengua española acerca de la inclusión de las unidades fraseológicas, con una especial atención a las locuciones y a las colocaciones.

${ }^{2}$ Para nuestro estudio hemos tenido en cuenta los datos que aparecen en los prólogos, las presentaciones, las guías del lector, las notas del editor, las abreviaturas, las advertencias preliminares y las guías para la consulta de los diccionarios.
} 
Antes de emprender el análisis, vamos a detenernos en algunas cuestiones vinculadas con nuestro interés y que están relacionadas con la noción de colocación, la consideración de las colocaciones en la investigación fraseológica y la presencia de las colocaciones en la praxis lexicográfica.

\section{LA NOCIÓN DE COLOCACIÓN}

A pesar de que en los últimos años se hayan incrementado considerablemente las investigaciones específicas interesadas por las colocaciones en la lengua española y contemos con útiles descripciones sobre el estado de la cuestión, ${ }^{3}$ todavía entre los estudiosos del tema el término colocación provoca múltiples interpretaciones (Wotjak 1998). Entre las diversas razones que se han barajado para justificar los diferentes conceptos manejados, una de las tesis más aceptadas tiene que ver con el hecho de que los estudios sobre colocaciones no cuentan con una larga tradición en la filología española. Aunque fuera Firth (1957) quien dentro de la corriente del contextualismo británico empleara por primera vez collocation para nombrar un tipo de combinaciones frecuentes de unidades léxicas, ${ }^{4}$ en la lingüística desarrollada en España las más tempranas alusiones al término colocación no se producen hasta finales de los años 70, concretamente para hacer referencia al contorno que presenta una unidad léxica en el diccionario (Corpas Pastor 1996: 61-63). Habrá que esperar a la década de los 90 para encontrarnos con las primeras investigaciones ${ }^{5}$ en las que se estudien las unidades implicadas en este fenómeno, y desde entonces el término colocación ha sido entendido y empleado de diversas maneras. Por otro lado, la variedad de denominaciones existentes para nombrar este fenómeno léxico, ${ }^{6}$ los diferentes tipos de colocaciones que se han propuesto ${ }^{7} \mathrm{y}$ el que se haya abordado el concepto de colocación desde diferentes niveles de análisis lingüístico (sintáctico, semántico, léxico, fraseológico), puede interpretarse también como otra consecuencia más de la señalada juventud de la noción de colocación en la investigación hispánica.

Con relación a la definición del término colocación y al establecimiento de sus características, la bibliografía específica que se ha ocupado del tema ha puesto de manifiesto que son varias las perspectivas teóricas y metodológicas desde las que se ha emprendido la delimitación lingüística de lo que es o no es una colocación. En este sentido, Bosque (2004: CLII-CLVIII) se ha referido a dos grandes corrientes:

${ }^{3}$ Los trabajos de Alonso Ramos (1994-1995), Bosque (2001), Castillo Carballo (1998), Corpas Pastor (1996: 53-65) o Koike (2001: 16-25) son un excelente botón de muestra.

${ }^{4}$ Con anterioridad, Bally (1909) ya había destacado la preferencia que muestra la lengua a la hora de relacionar unos términos con otros, y utilizó la denominación groupements usuels para referirse a aquellas combinaciones cuyo grado de cohesión no es absoluto y cuyos componentes mantienen su autonomía semántico-sintáctica y ayudan a esclarecer el sentido unitario de la expresión (avoir de la chance). El mencionado autor distinguió estas construcciones de las combinaciones libres y ocasionales (avoir une maison) y de las combinaciones completamente fijas e indisolubles (avoir lieu).

${ }^{5}$ Vid. los trabajos citados por Corpas Pastor (1996: 63), Koike (2001: 21-25) y Penadés Martínez (2001: 58).

${ }^{6}$ Aguilar-Amat Castillo (1993: 267) ha recogido las siguientes: solidaridades léxicas, lexías complejas, combinaciones, combinaciones recurrentes, concurrencias, coocurrencias, coapariciones, colocaciones o conlocaciones.

${ }^{7}$ Para una revisión de la taxonomía de las colocaciones, pueden consultarse las investigaciones de Corpas Pastor (1996: 66-76), Hausmann (1998: 67), Írsula Peña (1994: 281), Koike (2001: 45-46) y Penadés Martínez (2001). 
a) Para la primera de esas corrientes, desde una perspectiva estadística, el concepto de colocación está relacionado con la frecuencia de coaparición de dos unidades léxicas. Sinclair (1991), máximo exponente de la defensa de esta teoría dentro del contextualismo británico, considera que una colocación es la coocurrencia de dos o más palabras que aparecen con cierta frecuencia en el discurso, de manera que su búsqueda puede realizarse midiendo, entre otros aspectos formales, la frecuencia de cada uno de los colocados, la distancia que hay entre ellos en un texto y el número de veces que se muestran juntos. ${ }^{8}$ Utilizando el criterio de la frecuencia de coaparición de una determinada combinación, también para la lengua española García Godoy (1994) y Pamies Bertrán y Pazos Bretaña (2003) han estudiado las combinaciones colocacionales en un corpus escrito.

b) En cuanto a la segunda de las aproximaciones a las que se refiere Bosque, en términos más lexicográficos, las colocaciones son «el resultado de dar forma léxica a ciertas relaciones semánticas que se pueden describir formalmente» (Bosque 2004: CLIII). Esta línea está representada por los trabajos que recurren a la noción de función léxica, ${ }^{9}$ en virtud de la cual justifican las restricciones combinatorias de una lengua, esto es, las relaciones semánticas que hay entre dos unidades léxicas que presentan una coocurrencia restringida. ${ }^{10}$ Siguiendo este marco, Alonso Ramos (2002: 67) define las colocaciones como «construcciones semi-fraseológicas formadas por dos $\mathrm{UL}, \mathrm{L}_{1} \mathrm{~L}_{2}$, en donde $\mathrm{L}_{2}$ es escogida de un modo (parcialmente) arbitrario para expresar un sentido dado y/o un papel sintáctico en función de L1». Ello quiere decir que en la colocación error garrafal el adjetivo garrafal es elegido para indicar el significado 'grande' con relación a error.

Además de las dos orientaciones mencionadas, las colocaciones también han sido abordadas a partir del concepto de solidaridad léxica propuesto por Coseriu (1977: 148), ${ }^{11}$ definido en los siguientes términos:

determinación semántica de una palabra por medio de una clase, un archilexema o un lexema, precisamente, en el sentido de que una clase determinada, un determinado archilexema o un de-

${ }^{8}$ Alonso Ramos (1994-1995: 14) resta validez a la utilización del criterio formal (uso de probabilidades y frecuencias) a la hora de emprender la detección de una colocación, pues la coocurrencia frecuente de dos unidades léxicas (por ejemplo, gaviota puede tener en un corpus una probabilidad elevada de aparecer con blanca) no implica que estemos siempre ante una colocación (gaviota blanca no es una colocación). De este mismo parecer es Bosque (2001: 11), al considerar que las aproximaciones basadas estrictamente en términos estadísticos no son las acertadas para definir el concepto.

${ }^{9}$ El enfoque teórico subyacente a la función léxica está en el marco de la teoría Sentido-Texto de Mel'čuk y Zolkovskij (1970). En la lingüística española, Alonso Ramos (1994-1995: 22) utiliza también la noción de función léxica y la define de la siguiente manera: «es un sentido o un papel semántico-sintáctico tal que su expresión depende del lexema al que FL se aplica». Aunque en términos generales la teoría Sentido-Texto consigue explicar muchas de las relaciones semánticas que se producen entre dos lexemas gracias a las funciones léxicas, Koike (2001: 50) es de la opinión de que las funciones léxicas «no parecen cubrir todas las posibles relaciones semánticas que hay en las colocaciones sustantivo-adjetivo. Por ejemplo, no se sabe qué función léxica desempeña el adjetivo adquisitivo en poder adquisitivo o el adjetivo lacio en pelo lacio».

${ }^{10}$ La utilización de las funciones léxicas como elemento organizador lexicográfico aparece en el Dictionnaire explicatif et combinatoire du français contemporain. Una presentación de los procedimientos aplicados en el diccionario citado y la muestra de algunas ilustraciones pueden consultarse en Mel'čuk (1993: 102-110).

${ }^{11}$ La primera referencia de su trabajo es de 1966. 
terminado lexema funciona como rasgo distintivo de la palabra considerada. Dicho de otro modo, se trata del hecho de que una clase, un archilexema o un lexema pertenece a la definición semántica de esa palabra.

De los dos tipos de solidaridares léxicas establecidos por Coseriu: solidaridades unilaterales (morder-dientes) y solidaridades multilaterales (ladrar-perro, relinchar-caballo, arrullarpaloma), sólo las segundas coincidirían parcialmente con el fenómeno de la colocación, pues los constituyentes de las primeras no suelen aparecer juntos en el discurso (Koike 2001: 18). Sin embargo, como muy bien ha demostrado Corpas Pastor (1996: 65), «la noción de colocación es más amplia que la de solidaridad, puesto que no es posible explicar una colocación como radicalmente opuesto a partir de esta última: ni radicalmente implica a opuesto, ni viceversa».

Otros estudiosos también han dirigido su atención hacia este tipo de combinaciones léxicas y han expuesto algunas definiciones que están muy próximas. Írsula Peña (1992: 160) considera que las colocaciones son «combinaciones frecuentes y preferentes de dos o más palabras, que se unen en el seno de una frase para expresar determinados acontecimientos en situaciones comunicativas establecidas». De «combinatoria preferente» habla también AguilarAmat Castillo (1993: 267) para referirse a la asociación que se produce de unas palabras con otras para manifestar una realidad determinada. En esta misma línea, para Corpas Pastor (1996: 66) las colocaciones son «aquella propiedad de las lenguas por la que los hablantes tienden a producir ciertas combinaciones de palabras entre una gran cantidad de combinaciones teóricamente posibles». Las combinaciones que resultan, a las que considera unidades fraseológicas, «están formadas por dos unidades léxicas en relación sintáctica, que no constituyen, por sí mismas, actos de habla ni enunciados; y que, debido a su fijación en la norma, presentan restricciones de combinación establecidas por el uso, generalmente de base semántica: el colocado autónomo semánticamente (la base) no sólo determina la elección del colocativo, sino que, además, selecciona en éste una acepción especial, frecuentemente de carácter abstracto o figurativo». Con anterioridad, Hausmann (1979: 191-192) ya se había referido también a las colocaciones como combinaciones restringidas en las que la base no necesita del colocativo para definirse, pero la definición del colocativo sí implica la presencia de la base.

Y por último, en la concepción de Bosque (2001, 2004: CLIV) las colocaciones son casos particulares de relaciones de selección léxica, más concretamente, una colocación es una combinatoria léxica restringida. Ello quiere decir que con con las manos en la masa formaríamos una colocación, puesto que los verbos a los que modifica forman parte de una clase léxica integrada por pillar, coger, atrapar, capturar, agarrar y detener, o de la clase léxica establecida por sorprender, descubrir «y algún otro verbo cercano» (Bosque 2001: 23). El hecho de que esos verbos no puedan reemplazarse por otros demuestra que la selección léxica que la locución adverbial realiza con relación al evento del que se predica es restringida.

\section{LAS COLOCACIONES EN LA INVESTIGACIÓN FRASEOLÓGICA}

A la hora de revisar las distintas corrientes de investigación fraseológica que se han desarrollado en el siglo Xx, es manifiesto el interés con el que los lingüistas soviéticos, el estructuralismo europeo y los estudiosos anglo-americanos se han ocupado de estudiar las colocaciones (Corpas Pastor 2001: 42-43). Por lo que se refiere a la lingüística hispánica, son mu- 
chos los autores que suelen definir las colocaciones como un tipo concreto de unidades léxicas que constituyen una categoría intermedia entre las combinaciones léxicas libres y las combinaciones fijas o locuciones, ${ }^{12}$ por lo que han proliferado estudios en los que han sido tratadas las diferencias y las semejanzas que hay entre las colocaciones y los sintagmas libres, por un lado, y entre las colocaciones y las unidades fraseológicas, por otro. Aunque no existe un acuerdo todavía acerca de los criterios precisos que realmente marcan el límite de las colocaciones a ambos lados, en cuanto al problema de distinguir las colocaciones de las combinaciones libres, un buen número de investigaciones concluye que el que las colocaciones sean restricciones combinatorias fijadas por el uso repetido es lo que realmente las separa de las combinaciones libres (Koike 2001: 39; Zuluaga 1980, 2002: 105). Y en cuanto a la distinción entre las colocaciones y las unidades fraseológicas, en términos generales, la fijación formal y la idiomaticidad son consideradas las dos propiedades fundamentales de las unidades fraseológicas (Zuluaga 1980), frente a la fijación débil ${ }^{13}$ y al carácter semiidiomático ${ }^{14}$ que caracteriza a las colocaciones.

Con relación al estatus de las colocaciones dentro del ámbito de la fraseología, el desacuerdo entre los investigadores es manifiesto (Penadés Martínez 2005), de ahí que frente a la consideración de Corpas Pastor $(1996,1998,2001)$ de las colocaciones como un tipo particular de unidades fraseológicas, además de las locuciones y los enunciados fraseológicos, ${ }^{15}$ Bosque (2004: CLV-CLVI) afirme que la combinatoria léxica restringida no forma parte de la fraseología, y una de las razones que aduce se relaciona con el hecho de que las necesidades conceptuales que la lengua contiene no tienen nada que ver con la fijación idiomática. ${ }^{16}$ Otros estudiosos mantienen una posición intermedia sobre el tema al defender que las colocaciones están a medio camino entre las combinaciones libres de palabras y las unidades fraseológicas, dado que presentan rasgos propios de una y de otra clase de unidades (Alonso Ramos 19941995, 2002: 64; Ruiz Gurillo 1997: 87-88). El hecho de que las colocaciones puedan constituir una especie de intersección entre las combinaciones libres y las unidades fraseológicas no impide que Zuluaga (2002: 111) considere que con las colocaciones estamos ante una clase diferente y «que deberían separarse adecuadamente na práctica lexicográfica» (Zuluaga 1997: 24).

${ }^{12}$ Vid., para esta cuestión, Corpas Pastor (1996: 53) y Koike (2001: 14).

${ }^{13}$ La fijación se produce a nivel de uso pero no en el sistema de la lengua.

${ }^{14}$ Frente a la falta de correspondencia que hay entre el significado global de una unidad fraseológica (poner de vuelta y media) y el significado individual de cada uno de sus componentes, las colocaciones desde el punto de vista semántico pueden ser parcialmente composicionales (dinero negro) o totalmente composicionales (locamente enamorado).

${ }^{15}$ Según Corpas Pastor (1998: 43-46), en las colocaciones se dan los rasgos distintivos de las unidades fraseológicas: polilexicalidad, alta frecuencia de aparición y de coaparición, institucionalización, estabilidad (fijación y especialización semántica), idiomaticidad y variación potenciales.

${ }^{16}$ En un trabajo anterior, Bosque (2001: 10 y 21-22) ya había adelantado que las propiedades que caracterizan a las colocaciones determinan que su estudio forme parte de la interfaz léxico-sintaxis y no pertenezca al campo de estudio de la fraseología.

${ }^{17}$ Alonso Ramos está dirigiendo en estos momentos el Diccionario de colocaciones del español (DiCE), primer diccionario de colocaciones para la lengua española. Para conocer el proceso de elaboración del diccionario y la organización de la información en el artículo lexicográfico, puede consultarse la página electrónica $<$ http://www.dicesp.com>. 


\section{LAS COLOCACIONES EN LOS DICCIONARIOS}

Aunque la lengua española no disponga todavía de diccionarios específicos de colocaciones, ${ }^{17}$ sí contamos con diccionarios monolingües generales de lengua en los que los lexicógrafos, en menor o en mayor medida, incluyen información colocacional en algunos lemas. A pesar de que las colocaciones estén presentes en los diccionarios, es innegable que este fenómeno léxico sigue estando desatendido por la lexicografía española, ${ }^{18}$ pues frente a la abundancia con la que son recogidos y marcados las locuciones y los enunciados fraseológicos en los diccionarios monolingües del español, ${ }^{19}$ las colocaciones no son recolectadas con la sistematicidad que todos desearíamos. El hecho de que los diccionarios sean escuetos a la hora de recoger las relaciones léxico-semánticas sintagmáticas (Alonso Ramos y Sanromán Vilas 2000: 97) y la novedad que ha supuesto en los estudios lingüísticos el concepto de colocación (Bargalló Escrivá y otros 1997-1998) son, entre otros, algunos de los razonamientos que se barajan a la hora de justificar por qué las colocaciones no han sido objeto de un tratamiento regular en los diccionarios, y por qué no se encuentran registradas de una manera exhaustiva y marcadas como tales fraseologismos en los repertorios lexicográficos. Esta situación no impide, sin embargo, que las colocaciones estén presentes, si bien de una manera no explícita, en la microestructura de muchos diccionarios monolingües del español gracias al empleo de diferentes mecanismos (en la alusión que se hace en la definición a las restricciones semánticas combinatorias que tiene una palabra, en los ejemplos que completan la información que aparece en la definición, en el empleo de algunas fórmulas (aplícase a, referido a, etc.) para destacar las restricciones semánticas del lema, bajo el marbete de locuciones o frases, etc.). ${ }^{20} \mathrm{La}$ inclusión de las colocaciones en la microestructura de los diccionarios ha acaparado la atención de un buen número de trabajos, los cuales se han ocupado de presentar las dificultades que acarrea al alumno extranjero el exclusivo enfoque descodificador que tienen muchos diccionarios y la inclusión de las colocaciones en las entradas de los colocativos, ${ }^{21}$ cuando es realmente en la fase de la producción de las colocaciones y en la selección correcta del colocativo donde los aprendices encuentran las mayores dificultades (Penadés Martínez 2004: 60). Por ende, lo más acertado sería que los diccionarios, además de la descodificación, permitieran también la codificación de las colocaciones, gracias a su inclusión en el artículo lexicográfico correspondiente a la base, ${ }^{22}$ que suele ser siempre la palabra que el alumno conoce y siente más cercana.

${ }^{18}$ Este hecho ha sido especialmente resaltado, entre otros, por Alonso Ramos (1994-1995: 9) y Castillo Carballo (2001c: 156).

${ }^{19} \mathrm{El}$ tratamiento lexicográfico de las unidades fraseológicas en los diccionarios ha acaparado la atención de un buen número de investigaciones (vid., entre otras, Castillo Carballo 2001c, Martínez Marín 1991 y Olímpio de Oliveira Silva 2007), lo que no quiere decir que todas las unidades fraseológicas hayan sido examinadas con la misma intensidad, ni que la fraseología haya recibido una atención uniforme en los diferentes diccionarios del español, pues es evidente la diversidad de procedimientos, abreviaturas y tipos de definición empleados en su recogida (Déniz Hernández 2000: 386).

${ }^{20}$ Vid., entre otras investigaciones, Alonso Ramos (2002), Castillo Carballo (2000, 2001a, 2001b), Hausmann (1998) y Ruiz Martínez (2005).

${ }^{21}$ Para más información sobre esta manera de proceder, vid. Castillo Carballo (2001a: 404, 2001c: 156) y Hausmann (1979: 192).

${ }^{22}$ Este enfoque es el seguido por el Diccionario de colocaciones del español (DiCE). 


\section{ANÁLISIS DEL CORPUS DE DICCIONARIOS}

Para realizar nuestro estudio, hemos trabajado con una selección representativa de diccionarios de la lengua española, adscritos a uno de estos tres grupos:

1. Diccionarios generales.

2. Diccionarios didácticos dirigidos a estudiantes de español como lengua materna o a estudiantes de español como segunda lengua.

3. Diccionarios fraseológicos.

Todos los ejemplos de colocaciones que hemos tomado de los diferentes diccionarios examinados, presentados en los Anexos, están contenidos en las informaciones que nos proporcionan el Diccionario de uso del español (DUE) y el Diccionario del español actual (DEA). Y ello no obedece a que las dos obras citadas sean diccionarios exclusivos de colocaciones o a que en ellas las construcciones colocacionales aparezcan etiquetadas o agrupadas como tales, sino al hecho de que tanto en el $D U E$ como en el $D E A$ se registren las palabras de la lengua prestándose, en algunos casos, una atención pormenorizada a su combinatoria léxico-sintáctica. Es decir, utilizaremos la praxis lexicográfica para decidir que las construcciones que proponemos son colocaciones, puesto que los autores de los diccionarios mencionados, al considerar que para una acepción determinada un lema se construye con una unidad léxica concreta, implícitamente están presentando una importantísima información para poder otorgar a unas determinadas combinaciones léxicas el estatus de colocaciones. Además, tanto el $D U E$

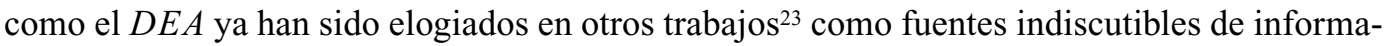
ción colocacional en su microestructura, gracias al empleo de diferentes procedimientos.

\subsection{DiCCIONARIOS GENERALES}

\subsubsection{Real Academia Española (1884): Diccionario de la lengua castellana ${ }^{24}$}

Es en la duodécima edición del Diccionario de la lengua castellana, del año 1884, cuando por primera vez la Real Academia Española recoge en las páginas de presentación del diccionario, concretamente en el apartado reservado a las Reglas para el uso de este diccionario, que si

el artículo es de sustantivo, se registran después de las acepciones propias del vocablo aislado las que resultan de la combinación del sustantivo con un adjetivo, con otro sustantivo regido de preposición ó con cualquiera expresión calificativa (p. XIX).

La consulta de la información que presenta el diccionario en el artículo lexicográfico de algunos sustantivos, nos permite comprobar que después de la acepción o acepciones particulares que tiene un sustantivo se listan diferentes combinaciones léxicas formadas por un sustantivo y otras clases de palabras entre los que se establece una relación sintáctica, de manera que el sustantivo aparece modificado por el adjetivo u otras clases de palabras que realizan esta función calificativa. Algunas de las construcciones léxicas que aparecen en este espacio del artículo lexico-

${ }^{23}$ De estos estudios daremos cuenta en el espacio reservado para el análisis de cada diccionario.

${ }^{24} \mathrm{El}$ análisis que exponemos sobre el diccionario académico forma parte de una comunicación que presentamos en el $V$ Congreso Internacional de Historiografía Lingüistica (Murcia, 7-11 de noviembre de 2005); vid. Ruiz Martínez (2006). 
gráfico se comportan como verdaderas colocaciones, pues en ellas el sustantivo es el colocado autónomo semánticamente y el colocativo puede ser un adjetivo u otra clase de palabra que desempeña las funciones propias de éste. En este sentido, las combinaciones lujo asiático y diente de leche, contenidas en la duodécima edición del $D R A E$, son un claro ejemplo de colocaciones:

Lujo. [...] || asiático. El extremado.

Diente. [...] || de leche. [...] || Cada uno de los que salen el primer año, porque son pequeños y muy blancos.

En las sucesivas ediciones del diccionario académico (Diccionario de la lengua castellana, en las ediciones de 1899 y 1914, y Diccionario de la lengua española, ${ }^{25}$ a partir de la edición de 1925 y siguientes — 1936, 1939, 1947, 1956, 1970, 1984, 1992-) se volverá a repetir la misma cita que hemos reproducido en el párrafo anterior, en el espacio reservado a dar cuenta de las $R e$ glas para el uso de este diccionario. ${ }^{26}$ Cualquier usuario del diccionario podrá comprobar que se sigue respetando el mismo espacio y el mismo procedimiento a la hora de recoger las construcciones colocacionales sustantivo + adjetivo dentro del artículo lexicográfico correspondiente al sustantivo que funciona como la base de una colocación. Sin embargo, esta no es la única manera de proceder que tiene el diccionario académico a la hora de incluir una colocación, pues hay casos en los que la consulta de su microestructura, ${ }^{27}$ en las diferentes ediciones, nos ha llevado a detectar una colocación dentro del artículo correspondiente al adjetivo que funciona como colocativo en la colocación, de acuerdo con los siguientes procedimientos:

a) La colocación se encuentra en la propia definición que se ofrece del adjetivo. Este es el caso de la colocación momento crucial:

crucial. [...] || 2. fig. Dícese del momento o trance crítico en que se decide una cosa que podía tener resultados opuestos (DRAE-1984)..$^{28}$

b) La colocación se halla en los ejemplos que aclaran la definición. A modo de ilustración, citamos la colocación odio mortal:

mortal. [...] || 5. Aplícase también a aquellas pasiones que mueven a desear a uno la muerte. Odio MORTAL; enemistad MORTAL (DRAE-1984).

Por otro lado, el hecho de que sea en la duodécima edición del diccionario académico cuando por primera vez podamos vislumbrar en sus páginas preliminares una posible alusión, aunque sea de manera implícita, a las construcciones colocacionales, no nos puede llevar a pensar que en las once ediciones anteriores no se les presta atención a estas combinaciones lé-

${ }^{25}$ Según la Academia, la nueva denominación es una consecuencia de la «mayor atención consagrada a las múltiples regiones lingüísticas, aragonesa, leonesa e hispanoamericana, que integran nuestra lengua literaria y culta» («Advertencia», p. VIII).

${ }^{26}$ A partir de la decimonovena edición (1970) la nueva denominación que se le da a este apartado es Advertencias para el uso de este diccionario. También en esta edición y en las siguientes se observa otra modificación con relación a las anteriores, pues se ofrecen separadas y numeradas todas las advertencias presentadas, insertándose la cita que estamos analizando en el número III. Orden de acepciones en cada artículo.

${ }^{27}$ En Castillo Carballo (2000) y Ruiz Martínez (2005) se hace referencia a los diferentes medios que utiliza el diccionario académico para ofrecer información colocacional en su microestructura.

${ }^{28}$ El uso de marcadores restrictivos (dicese de) sirve en el diccionario para presentar las bases de las colocaciones. 
xicas en la microestructura del diccionario. Basta con consultar, a modo de ejemplo, el artículo lexicográfico correspondientes al sustantivo hombre para comprobar que en todas las ediciones se recoge la colocación hombre de bien:

HOMBRE. [...] HOMBRE DE BIEN. Se llama al hombre honrado, de verdad, y que cumple puntualmente sus obligaciones: y tambien se toma por el que es noble. Optimus vir, nobilitate, vel provitate commendatus (DRAE-1780).

Además de las construcciones colocacionales aludidas, resulta fácil encontrar otro tipo de colocaciones, integradas por un sustantivo + preposición + sustantivo, que de acuerdo con Corpas Pastor (1996: 74) «indican la unidad de la que forma parte una entidad más pequeña o bien el grupo al que pertenece un determinado individuo». Dentro del primer grupo estaría la colocación tableta de chocolate, mientras que la colocación enjambre de abejas integraría el segundo grupo. Generalmente, estas construcciones colocacionales suelen aparecer bajo la entrada del primer sustantivo. Este es el caso de diente de ajo o banco de peces:

Diente. [...] $\|$ de ajo. Cada una de las partes en que se divide la cabeza del ajo, separadas por su tela y cáscara particular (DRAE-1925).

Banco. $[\ldots] \|$ 8. Conjunto de peces que en gran número van juntos; como las sardinas y los atunes (DRAE-1939).

Sin embargo, este nuevo tipo de colocaciones también puede aparecer en la microestructura de las diferentes ediciones del diccionario siguiendo otros dos procedimientos:

a) Como ejemplos al final de una acepción. Así nos encontramos la colocación pastilla de jabón:

pastilla. (d. de pasta) f. Porción de pasta de uno u otro tamaño y figura, y ordinariamente pequeña y cuadrangular o redonda. PASTILLA de olor, de jabón, de chocolate (DRAE-1925).

b) En la propia definición. Este es el caso de rebanada de pan:

rebanada. (De rebanar) f. Porción delgada, ancha y larga que se saca de una cosa, y especialmente del pan, cortando del extremo al otro (DRAE-1936).

Junto a los dos tipos de colocaciones aludidos (sustantivo + adjetivo y sustantivo + preposición + sustantivo), que son recogidos después de las acepciones particulares de un sustantivo, el diccionario académico incluye también otras clases de combinaciones léxicas que nada tienen que ver con las colocaciones. Nos estamos refiriendo concretamente a las locuciones (luna de miel) ${ }^{29}$ y a los compuestos sintagmáticos (oso hormiguero). ${ }^{30}$ La consulta y lectura de la microestructura de la duodécima edición del diccionario y las siguientes nos lleva a afirmar

${ }^{29}$ Para la distinción entre locución y colocación resultan muy útiles los criterios expuestos por Aguilar-Amat Castillo (1993), Corpas Pastor (1996) y Ruiz Gurillo (1997 y 2002); aunque ello no es óbice para que una determinada construcción aparezca registrada unas veces como colocación y otras como locución. Este es el caso de las combinaciones retrato robot, telefonía móvil o tela asfáltica, tratadas como locuciones nominales por Corpas Pastor (1996: 95) y como colocaciones por Ginebra (2002). 
que en ningún momento se establece una distinción entre los tres tipos de construcciones, y su disposición dentro del artículo lexicográfico que corresponde a un sustantivo responde a criterios de ordenación alfabética.

Aunque la lectura de las Reglas para el uso de este diccionario de la duodécima edición del diccionario académico y las siguientes ediciones hasta el año 1992 solamente nos conduzca a hablar de un tipo concreto de colocaciones (sustantivo + adjetivo) en aquellas construcciones en las que un sustantivo es modificado por una o varias unidades léxicas, creemos que llegados a este punto es conveniente hacer alusión también a otras clases de colocaciones, que corresponden a los tipos de sustantivo (sujeto) + verbo y verbo + sustantivo (objeto), de las que nada se anuncia en las páginas introductorias del diccionario, pero que después sí serán recogidas en su microestructura. Los dos recursos principales utilizados para dar cuenta de estas colocaciones son:

a) La colocación se incluye en la definición. Este es el caso de correr un rumor:

correr. [...] 9. Hablando de noticias, rumores, etc., circular, propalarse, difundirse (DRAE-1970).

b) La colocación aparece en el ejemplo con el que se pretende completar la definición de una acepción. Ejemplo: dar un abrazo:

dar [...] 21. Junto con algunos sustantivos, hacer, practicar, ejecutar la acción que estos significan. DAR un abrazo, por abrazar; DAR saltos, por saltar (DRAE-1992).

Por otro lado, desde la edición del año 1884 hasta la del año 1992, el diccionario académico siempre ha venido separando claramente, dentro de las Reglas para el uso de este diccionario (p. XIX), el párrafo dedicado a dar cuenta de la ubicación de las acepciones que tiene un sustantivo cuando se combina con un adjetivo, con otro sustantivo o con cualquier otra expresión calificativa (p. XIX) -espacio en el que, como ya hemos puesto de manifiesto, pueden encontrarse las colocaciones del tipo sustantivo + adjetivo-, de las líneas en las que se hace alusión a las unidades fraseológicas. A estas últimas construcciones las denomina frases o expresiones $^{31}$ y bajo ese marbete las páginas introductorias del diccionario académico nunca han incluido ningún ejemplo de colocaciones.

${ }^{30}$ Las colocaciones y los compuestos sintagmáticos son dos fenómenos léxicos que están muy próximos, pues en la lengua se produce una evolución desde las combinaciones libres de palabras hasta las colocaciones, y de éstas hasta los compuestos sintagmáticos (Aguilar-Amat Castillo 1993). Ferrando Aramo (2002) se ha ocupado de las diferencias que hay entre las dos construcciones, centrando su análisis en la fijación y en el modo de significar, y concluye que el hecho de que los compuestos sintagmáticos sean «secuencias denominativas» (p. 104) es posiblemente el rasgo más notable que permite separarlos de las colocaciones. En Ruiz Gurillo (2002) se listan 16 rasgos cuya presencia o ausencia no sólo nos permiten establecer la distinción entre colocaciones y compuestos, sino que también nos sirven para perfilar el concepto de locución. La difusa frontera que separa en ciertos casos todas estas construcciones léxicas origina clasificaciones de algunas combinaciones con las que no todos están de acuerdo. A modo de ejemplo, presentamos hombre clave o visita relámpago, consideradas por Corpas Pastor (1996: 73) colocaciones y por Koike (2001: 46) un claro ejemplo de composición.

${ }^{31}$ Será a partir de la edición de 1970 cuando se les dedique un espacio independiente a estas construcciones para informar de su ubicación en el artículo correspondiente a uno de los vocablos de que constan ( $V$. Cómo encontrar la definición de expresiones formadas por varios vocablos, p. XXIV). Asimismo, será la primera vez que de manera explícita se diga al lector en estas páginas qué tipo de expresiones son las que se incluyen dentro de este grupo, pues se habla de frases hechas (en buenas manos está el pandero), locuciones (no dar [uno] pie con bola) y modos adverbiales (ni con mucho). En la edición de 1970 los refranes serán excluidos de la obra académica. 
Reservamos un apartado independiente en nuestra revisión para la vigésima segunda edición del $D R A E$ (2001), en la que encontramos algunos cambios significativos con relación a la información que las ediciones anteriores contenían en sus páginas introductorias acerca de las construcciones objeto de nuestro estudio. En esta edición la Academia utiliza por primera vez el término formas complejas al afirmarse en el apartado 3.3., Colocación de las formas complejas dentro del Diccionario (p. XL), que

además de registrar las entradas constituidas por una sola palabra (p. ej., perla, aceite, susto), el Diccionario recoge series de palabras que, combinadas de una determinada manera, expresan conceptos no interpretables mediante la simple adición de los significados de sus componentes (de perlas, aceite virgen, no ganar para sustos). Para localizar estas entradas, a las que denominamos formas complejas, dentro del Diccionario, recurrimos a las normas siguientes:

Las combinaciones estables de un elemento sustantivo con otras palabras que, con respecto a él, desempeñan una función adjetiva (ya sean adjetivos, nombres en aposición, complementos con preposición, etc.), irán siempre en el artículo correspondiente al elemento sustantivo. P. ej., aceite virgen se encontrará en el artículo encabezado por la palabra aceite; buena mano en el artículo mano; agua de Colonia en agua, etc. $[\ldots] . .^{32}$

Junto a la relación de formas complejas ofrecidas en este listado, tenemos otros ejemplos en la p. XXIX, a través de los cuales se da cuenta de la variación de género en los lemas de algunas formas complejas. Será justamente en este espacio en el que nos encontremos con la colocación abogado de oficio:

abogado, da. [...] $\| \sim$ de oficio. $m$ y f. Jurista asignado por el juez a una parte, ordinariamente por su falta de recursos económicos.

Esta manera de proceder es muy significativa, pues es la primera vez que la Academia utiliza una denominación concreta para las combinaciones léxicas que venimos incluyendo en el concepto de colocación. Además de las colocaciones, bajo la etiqueta formas complejas la Academia también acoge otras construcciones que, como ya hemos señalado anteriormente, están muy próximas a las anteriores; nos estamos refiriendo a los compuestos sintagmáticos, como, por ejemplo, agua de Colonia, y a las locuciones nominales, como es el caso de caballo de batalla o mano de santo.

Aunque la Academia incorpore bajo el mismo marbete el concepto de colocación (para el tipo sustantivo + adjetivo) y el de unidad fraseológica, ${ }^{33}$ sí establece una determinada organización a la hora de incluir todo este material en el diccionario. Las «combinaciones estables del lema con otros elementos que desempeñan una función adjetiva con respecto a él» ( $\mathrm{p}$. XLVII), según la Academia, constituirán el primer bloque de formas complejas que se incluyen en la entrada de un lema, y éste estará separado del segundo bloque de formas complejas (inte-

${ }^{32}$ El texto continúa ofreciendo información sobre la ordenación de carácter gramatical que ha seguido la Academia a la hora de documentar otras formas complejas. Los tipos propuestos son los siguientes: locuciones (fuera de combate), frases (subirse por las paredes) y expresiones (a la vuelta lo venden tinto) ( $\mathrm{p}$. XL). Según la Academia, todas estas formas complejas aparecerán tras una doble barra de mayor cuerpo que la que separa las acepciones de un lema. Vid. la información y los ejemplos que contiene el apartado 4.4., p. XLIII, destinado a las formas complejas, dentro del espacio en el que se da cuenta de la Estructura de los artículos del Diccionario (pp. XLII-XLIII).

${ }^{33}$ Además del concepto de locución nominal y compuesto sintagmático. 
grado por «locuciones, expresiones, frases e interjecciones», p. XLVII) por medio de una doble barra de mayor cuerpo que la que va distinguiendo las distintas acepciones de un lema. ${ }^{34}$

\subsubsection{Real Academia Española (1927): Diccionario Manual e Ilustrado de la Lengua Española}

En la p. VIII de las «Advertencias» del Diccionario Manual e Ilustrado de la Lengua Española (DMILE) leemos que

Cuando el artículo es sustantivo, después de las acepciones generales, se registran, con letra seminegrita, aquellas que resultan de la combinación del sustantivo con un adjetivo, con otro sustantivo regido de preposición, o de otra manera.

Es evidente que la Academia reproduce en esta cita las palabras que ya exponía en la duodécima edición del Diccionario de la lengua castellana, del año 1884. Siguiendo aquella manera de proceder, de nuevo la Academia vuelve a recoger, en el artículo lexicográfico ofrecido para un sustantivo, algunas construcciones léxicas que se comportan como verdaderas colocaciones, pues en ellas el sustantivo es el colocado autónomo semánticamente y el colocativo puede ser un adjetivo u otra clase de palabra que desempeña las funciones propias de éste. A tenor de esta información, la combinación limpieza en seco es un claro ejemplo de colocación:

limpieza. [...] || [en seco. Procedimiento de limpieza que no utiliza agua ni líquidos acuosos, sino una mezcla de hidrocarburos altamente disolventes de la grasa.

Tras la consulta de algunas de las acepciones que aparecen después de las acepciones generales en la microestructura del diccionario, podemos afirmar que también se ofrecen, además de las colocaciones, otros dos tipos diferentes de combinaciones léxicas: los compuestos sintagmáticos (coche cama) y las locuciones (diente de león). Al igual que en el diccionario académico, la Academia no propone una distinción entre los tres tipos de construcciones y su distribución a lo largo del artículo lexicográfico responde a un orden alfabético.

Además de informar de una colocación cuando la base es un sustantivo, en el DMILE también se registra información colocacional en los lemas correspondientes a los adjetivos y a los verbos. Junto al uso de la seminegrita para introducir colocaciones, en los artículos lexicográficos se emplean los siguientes recursos:

a) A través de la información contenida en el contorno. ${ }^{35}$ Los marcadores restrictivos dícese de, se dice, junto con se utilizan muy frecuentemente en el diccionario para lis-

${ }^{34}$ La Academia, al separar en el apartado 3.3. las combinaciones estables (dentro de éstas estarían las colocaciones) de las locuciones, frases y expresiones, implícitamente, parece estar considerando que las colocaciones no son unidades fraseológicas, frente a la opinión de quienes sí creen que las colocaciones son fraseologismos, e incluso frente a la opinión de quienes las tratan como unidades semi-fraseológicas.

${ }^{35}$ Bosque (2004: CVIII) ha calificado el contorno de «poderoso instrumento restrictivo». Siguiendo a Bosque (2004: CVIII-CIX), diremos que los contornos de las definiciones se pueden presentar de diferentes formas: dicho de, dícese de, referido a, aplicado a, hablando de, etc., y a través de distintas convenciones: mediante flechas, con corchetes, en un tipo de letra distinto, etc. La consulta de éste y otros diccionarios pone de manifiesto que con bastante frecuencia el contorno se convierte en un instrumento útil de información colocacional. 
tar los sustantivos con los que suele aparecer un determinado adjetivo o verbo. A modo de ejemplo, puede consultarse la colocación batalla encarnizada:

encarnizado, da. [...] Dícese de la batalla, riña, etc., muy porfiada y sangrienta.

b) En el ejemplo que sirve para ilustrar la definición propuesta para el lema. La colocación guardar la ley se presenta de esta manera:

guardar [...] Observar y cumplir lo que cada uno debe por obligación. GUARDAR la ley, la palabra, el secreto.

En otros casos, los ejemplos sirven para introducir y contextualizar una colocación. Este es el caso de fumador empedernido:

empedernido, da. [....] [incorregible, se dice de la persona que tiene un vicio o una costumbre muy arraigada: Es un fumador EMPEDERNIDO.

c) En la definición de un lema. Siguiendo este procedimiento se registra la colocación rescindir una obligación:

rescindir. tr. Dejar sin efecto un contrato, obligación, etcétera.

\subsubsection{Moliner (1966-1967): DUE}

La información colocacional que ofrece el DUE no sólo es apreciable en la consulta de su microestructura, ${ }^{36}$ sino también en sus partes introductorias, tal y como ponen de manifiesto las alusiones directas al concepto de colocación.

a) A continuación, exponemos las aclaraciones precisas que se realizan en la Presentación (pp. IX-XXX) del diccionario a propósito de las construcciones colocacionales.

1. En el apartado reservado para explicar los Catálogos de palabras afines (pp. X-XII) se afirma que

al final de ciertos artículos se incluye un catálogo de referencias en que figuran $[\ldots] 3 .^{\circ}$ Los equivalentes pluriverbales, en multitud de casos de uso más frecuente y más expresivos que la expresión monoverbal específica («hacer alusión» por «aludir»; «hacer reír» por «divertirse»; «dar por bueno» por «aprobar»; «dar la enhorabuena» por «felicitar»; «dar vueltas» por «girar»; «estar rabioso» por «rabiar»; «de ahora» en vez de «actual»... [...]) (p. x).

${ }^{36}$ El caudaloso contenido colocacional que registra este diccionario ha sido puesto de manifiesto, entre otros autores, por Alonso Ramos (1994-1995: 18), quien ha reconocido que «A pesar de algunas inconsistencias y so pena de ser acusada de tener devoción por María Moliner, tenemos que decir que su diccionario es el que mejor trata las colocaciones en español», Calderón Campos (1994b), Alvar Ezquerra (2000), Castillo Carballo (2000, 2002), Penadés Martínez (2001), Ruiz Martínez (2005) y Zuluaga (2002). Asimismo, Koike (2001: 42) para la confección de un corpus de colocaciones sustantivo-verbo ha revisado todas las entradas de los sustantivos de este diccionario, en virtud de la información que en el $D U E$ se ofrece sobre los verbos con los que puede combinarse un sustantivo para una determinada acepción. 
De la lectura de este párrafo deducimos que, como «equivalentes pluriverbales», el DUE acoge numerosas colocaciones del español, como es el caso de dar vueltas:

girar. [...] Moverse un cuerpo de modo que describe circunferencias alrededor de otro, o bien de modo que un punto o una línea de él mismo permanecen inmóviles y los demás puntos describen circunferencias alrededor de ellos. (V.: «ANDAR, ARRIBAR, BAILAR, [...] dar VUELTAS».

\section{En el apartado dedicado a las Expresiones pluriverbales (p. XII) se recoge que}

En muchos casos, se dan los adjetivos o adverbios con los que tiene una especial afinidad cierto nombre, adjetivo o verbo: «sueño ligero, profundo, reparador; cariño entrañable, sincero; nutridos aplausos; fatal resolución; empleo, pérdida, uso lastimoso; viva preocupación; profunda simpatía, antipatía; gloria, laurel inmarcesible; fe ciega; ruido infernal; caer pesadamente; referir punto por punto, con pelos y señales; honrado a carta cabal».

Las palabras de la autora indican que como «expresiones pluriverbales» en el $D U E$ van a localizarse numerosas colocaciones del tipo adjetivo + adverbio, nombre + adjetivo o verbo + adverbio. Como ejemplos de estos tres tipos de colocaciones, proponemos el caso de diametralmente opuesto, cariño entrañable y desear fervientemente:

diametralmente. Con los adjetivos «opuesto, distinto» o equivalentes, «completamente»: 'Mi concepto de la vida es diametralmente opuesto al suyo'.

entrañable (aplicado a «cariño» o nombre equivalente). Verdadero y profundo.

fervientemente. «Fervorosamente»: con fervor. [...] Con el verbo «desear» o equivalente, mucho, con mucha intensidad: 'Deseo fervientemente que ganes el premio'.

\section{En el apartado reservado para las Aclaraciones gramaticales (p. XII) se afirma que}

se indican para los verbos y adjetivos las preposiciones con que se construyen; para los nombres, los verbos que se unen a ellos para formar la frase: «Asentir (a), Consentir (en), Proveerse (de). Útil (a, para), Agradecido (a; por), Desagradecido (con)»; «actividad (Desplegar), alarma (Cundir; Sembrar), cólera (Deponer), conducta (Observar), suspiro (Dar, Exhalar), derrota (Infligir), incendio (Declararse, Estallar; Sofocar), desaliento (Cundir; Sembrar), velocidad (Imprimir), sueño (Conciliar), vigilancia (Ejercer; Montar; Extremar; Burlar)» (p. XIII).

De nuevo, encontramos una referencia a la inclusión de la información colocacional en la microestructura del diccionario, concretamente a aquellas colocaciones formadas por un nombre (sujeto u objeto) y un verbo. Esta manera de proceder, ofreciéndose junto al lema de un nombre, y entre paréntesis, los elementos léxicos con los que éste aparece, ha sido muy frecuente en este diccionario. Como ejemplos de colocaciones ofrecidas siguiendo este procedimiento, proponemos dar la alarma:

alarma. [...] 1 («Dar, Sonar la»). Voz o señal con que se avisa un peligro.

b) Además de la Presentación, también las Advertencias útiles para el manejo del diccionario (pp. XXXIXL-XLV) incluyen una referencia a la información colocacional que presenta este diccionario. En el apartado 5 dedicado al Orden dentro de cada artículo o 
acepción (pp. XLI-XLII), podemos leer que, después del lema, se incluyen entre paréntesis, entre otras anotaciones, advertencias de carácter gramatical, «tal como preposiciones con que se construyen los verbos o adjetivos, o verbos con que se construyen los nombres» (p. XLI).

Otra vez la autora del $D U E$ ofrece información sobre un tipo concreto de colocaciones, las formadas por un sustantivo (sujeto u objeto) + verbo.

c) Y por último, aparte de las orientaciones que se nos ofrecen tanto en la Presentación como en las Advertencias útiles para el manejo del diccionario a la hora de recoger colocaciones en su microestructura, la consulta de diferentes artículos lexicográficos nos permite afirmar que el diccionario acoge una interesante nómina de colocaciones gracias al empleo de diferentes procedimientos:

1. La colocación se desprende de la información contenida en el contorno que se ofrece del lema que funciona como colocativo. Con bastante frecuencia se utilizan los marcadores restrictivos aplicado a o se aplica $a$. Esta es la manera de presentar la colocación perdidamente enamorado:

perdidamente. Se aplica usualmente sólo a «enamorado» con el significado de «muy» o «muy violentamente».

2. La colocación se halla en la propia definición de un lema. De este manera, se incluye la colocación repicar las campanas:

repicar. [...] 3. intr. Sonar o tocar insistentemente las campanas, particularmente con toque vivo que expresa alegría.

3. Se da cuenta de una colocación en el ejemplo. Los ejemplos tienen un gran valor en este diccionario pues:

3.1. Unas veces contextualizan la colocación que ya se ha hecho explícita en la definición. Este es el caso de cerrar un trato.

cerrar. [...] 17 «Ultimar». Terminar y dar por completamente establecido un trato: 'Aún no he cerrado trato [el trato] con el dueño de la casa'.

3.2. En otros casos los ejemplos especifican la colocación completando el contenido de la definición. El ejemplo descubre explícitamente una serie de colocaciones que no aparecen incluidas en la definición del colocativo. Así se da cuenta en el diccionario de la colocación nevar copiosamente:

copiosamente. De manera copiosa: 'Nieva copiosamente'.

3.3. En el ejemplo queda a la vista la posposición o anteposición de un adjetivo en las colocaciones formadas por sustantivo y adjetivo: copiosa nevada, comida copiosa: 
copioso, -a. Abundante; se aplica a nombres de conjunto de cosas menudas: 'Una copiosa nevada. Una copiosa cabellera'. O formado por muchas cosas provechosas o estimables: 'Un copioso botín. Una copiosa cosecha de cereales. Una comida copiosa'.

4. La colocación aparece en las remisiones que ofrece una entrada, destacándose en versalita la palabra bajo la cual se encuentra definida. De este modo se presenta la colocación descubrir el pastel:

descubrir [...] V. «descubrir el CUERPO, descubrir la HILAZA, descubrir la OREJA, descubrir el PASTEL, descubrir el SANTÍSIMO».

5. Utilización de las marcas enlace frecuente, enlace muy frecuente o expresión muy frec. para localizar las colocaciones barajar citas, poner a salvo o locamente enamorado:

cita $[\ldots]$ BARAJAR CITAS. Enlace frecuente.

salvo, -a. [...] PONER A SALVO. Enlace muy frecuente.

locamente. «Con locura». Mucho o muy. (Expresión muy frec., «locamente enamorado.»).

6. La colocación puede agruparse en versalita y en renglón aparte junto a otras frases y modismos usuales, después de las acepciones de un lema. Este espacio será también el reservado por el $D U E$ para los compuestos sintagmáticos (casa de campo) y las locuciones nominales (pata de gallo). La colocación vida de perros, suministrada en la entrada vida, se ofrece en el mismo lugar en el que se listan otras unidades fraseológicas:

vida $[\ldots]$

V. PERRA [PERRA VIDA] o VIDA DE PERROS. «Vida arrastrada».

BUSCARSE LA VIDA [...]

DARSE LA GRAN VIDA $[\ldots]$

TENER SIETE VIDAS COMO LOS GATOS.

\subsubsection{A. C. Bolado, dir. (1988): Diccionario práctico de la Lengua Española}

En el espacio dedicado a la Estructura y uso de este diccionario ${ }^{37}$ se dice, a propósito de la estructura de las entradas, que las entradas léxicas del Diccionario práctico de la Lengua Española (DPLE) incluyen acepciones, subacepciones y locuciones (giros y frases hechas de uso generalizado). En cuanto a las subacepciones y las locuciones, se afirma que éstas «van alfabetizadas como si el conjunto fuera una sola palabra». Nuestra consulta de la microestructura del diccionario nos lleva a recoger colocaciones (hombre de bien), compuestos sintagmáticos (guardia civil) y locuciones nominales (asignatura pendiente) en el espacio destinado a las subacepciones, sin que exista ninguna distinción entre los tres tipos de unidades léxicas citadas.

HOMBRE [...] || de bien El que es probo e íntegro.

\footnotetext{
${ }^{37}$ No hay paginación en la introducción de este diccionario. La letra $a$ del diccionario empieza con 1.
} 
Por otro lado, algunos ejemplos de colocaciones han sido anotados en el espacio final del artículo lexicográfico destinado a documentar locuciones. Por esta razón, como frase hecha se presenta la colocación dar corte:

CORTE, 1 [...] dar c. Dar apuro, sofoco o vergüenza.

El diccionario incluye también otros tipos diferentes de colocaciones gracias a la información contenida en:

a) La definición. Así se documenta la colocación encapotarse el cielo:

encapotar. [...] Oscurecerse el cielo por las nubes, amenazar tormenta.

b) El contorno. El empleo de se dice de, se aplica a, con ciertos sust. como es muy frecuente en este diccionario para ofrecer colocaciones. De esta manera aparecen las colocaciones nariz aguileña, momento crucial o error craso:

AGUILEÑo, ÑA [...] || Se dice de las facciones delgadas y afiladas, y esp. de la nariz ganchuda.

CRUCIAL [...] Se aplica al momento decisivo o cumbre, en el desarrollo de un hecho.

CRASO, SA [...] || Con ciertos sust. como error, engaño, etc., imperdonable.

\subsubsection{Seco, O. Andrés y G. Ramos (1999): DEA ${ }^{38}$}

Todas las alusiones que en el $D E A$ encontramos acerca de combinaciones de palabras que pueden funcionar como una colocación aparecen en la Guía del lector (pp. XV-XXIII), concretamente en el apartado IV. Estructura de las acepciones (pp. XX-XXIII).

La primera referencia se presenta en el subapartado dedicado a La definición sinonímica y el contorno (pp. XXI-XXII), cuando a propósito de los elementos habituales del contorno se afirma que

los escribimos entre corchetes, indicando, cuando es preciso, la función que a cada uno corresponde en los enunciados vivos (sujeto, complemento directo, complemento con la preposición en, etc.) (p. XXII).

La consulta de la microestructura del diccionario nos permite comprobar que gracias a la información proporcionada por el contorno vamos a encontrar numerosas colocaciones. Este es el procedimiento seguido para dar cuenta de la colocación declararse un incendio:

\footnotetext{
${ }^{38}$ Este diccionario ha sido resaltado como una obra muy útil de información colocacional por Penadés Martínez (2001). La aplicación de la praxis lexicográfica como instrumento válido para delimitar las colocaciones de las locuciones, lleva a Penadés Martínez, a partir de las informaciones contenidas en el $D E A$, a determinar que son colocaciones algunas de las unidades fraseológicas que los autores del Diccionario fraseológico del español moderno $(D F E M)$ han catalogado como locuciones verbales. Penadés Martínez justifica por qué unidades fraseológicas como dar el espectáculo, dar el golpe o dar el pésame no funcionan en español como una locución verbal, sino como verdaderas colocaciones, pues en las entradas de espectáculo, golpe y pésame, el DEA incluye la acepción con la que aparecen estos tres sustantivos en las unidades citadas. Además, los autores del diccionario añaden que el sustantivo con esa acepción concreta se construye frecuente o generalmente con el verbo dar.
} 
declarar [...] 8 Comenzar a manifestarse [determinados fenómenos, esp. un incendio o enfermedad].

Además de los verbos, el contorno también ofrece información sobre aquellos elementos que habitualmente se van a agrupar con un nombre y con un adjetivo, tal y como se desprende de las dos citas que reproducimos a continuación:

En un nombre se ofrece con frecuencia esa información con respecto a complementos habituales (p. XXII).

En un adjetivo, cuando es conveniente, se informa por medio del corchete, no sólo sobre complementos habituales, sino sobre el nombre o tipo de nombre al que se refiere el adjetivo en la acepción dada (p. XXII).

Siguiendo estos procedimientos, en la microestructura del diccionario se documentan las colocaciones tableta de chocolate, cuando el lema es un sustantivo, y relación estrecha si el lema es un adjetivo:

tableta 1 Pieza rectangular, plana y poco gruesa [de un alimento sólido, esp. chocolate o turrón]. estrecho -cha [...] 3 [Relación, unión o colaboración] muy próxima.

La segunda referencia a las construcciones colocacionales, y utilizándose ahora el término colocación y el de construcción preferente, aparece en el subapartado que se ocupa de las Explicaciones complementarias a la definición (pp. XXII-XXIII), al afirmarse, con relación a las indicaciones sintácticas o sintáctico-semánticas que interesan a una acepción, que después del enunciado definidor el diccionario también incluye «la colocación o construcción preferente». De acuerdo con esta manera de proceder, nos encontramos en el diccionario con la colocación dar palique:

palique [...] 1 Conversación intrascendente o de puro entretenimiento. Frec en las constrs ESTAR $\mathrm{DE} \sim[$ con alguien], DAR $\sim$ [a alguien].

Además de los datos aportados por el contorno y de la información explícita que proporciona el diccionario después de la definición de un lema sobre una construcción preferente, también el $D E A$ ofrece algunos datos sobre la información colocacional por medio de:

a) Las citas que acompañan a las definiciones y acepciones. Estas citas sirven para:

- Completar la información aportada por el contorno. Así nos encontramos con la colocación fe ciega:

ciego -ga [...] 5 [Cosa no material] que se da sin reflexión y sin reservas. [...] Solo me queda el recuerdo. Y fe ciega en la bondad de los hombres.

- Ubicar explícitamente una colocación. Este es el caso de la colocación rogar encarecidamente:

encarecidamente adv. De manera encarecida. [...] Rogamos encarecidamente a cuantos deseen participar en alguna de las secciones de dicha exposición se sirvan remitir cuanto antes el boletín correspondiente. 
- Ejemplificar la información colocacional que se ha presentado después de la definición. Siguiendo este procedimiento aparece la colocación diametralmente opuesto:

diametralmente $a d v$. Completa o totalmente. Con el adj OPUESTO $u$ otro equivalente [...] Diametralmente opuesto [a Echegaray], el Padre Blanco García ... reconoce en Sellés cualidades poéticas, pero se muestra inflexible censor de la obra dramática.

b) La definición que se ofrece de un verbo que funciona como colocativo al incluir otros verbos sinónimos que también pueden formar parte de una colocación. De esta manera se recogen las colocaciones cumplir la ley y observar la ley, además de guardar la ley:

guardar [...] 5 Cumplir u observar [una ley, un precepto o una obligación].

c) Las acepciones numeradas $(1,2,3, \ldots)$ de un lema. De acuerdo con este mecanismo, nos encontramos con la colocación hombre de bien:

hombre $[\ldots] 12 \sim$ de bien, $\sim$ del día $\rightarrow$ BIEN $^{2}$, DÍA.

d) Las subacepciones concretas que forman parte del párrafo de la acepción, precedidas de las letras b), c), d). Gracias a esta información se da cuenta de la colocación diente de leche:

diente $1[\ldots]$ c) de leche $\rightarrow$ LECHE.

Con relación a otros conceptos afines, el $D E A$ separa claramente en sus páginas introductorias las referencias al concepto de colocación de las alusiones a las unidades léxicas compuestas o a las locuciones. Después en la microestructura, al igual que las colocaciones, también las locuciones y los compuestos sintagmáticos pueden presentarse o bien como acepciones del lema (locución: tabla [...] $14 \sim$ de salvación; compuesto sintagmático: cama [...] 8 elástica), o bien como subacepciones (locución: cortina [...] 1 [...] c) de humo; compuesto sintagmático: coche $[\ldots] \mathbf{1}[\ldots]$ c) de línea). Esta manera de proceder propicia que en algunos casos el usuario encuentre tres clases diferentes de combinaciones léxicas, esto es, colocaciones, locuciones y compuestos sintagmáticos, dispuestas como acepciones o subacepciones de un lema, y sin ninguna información aclaratoria que le permita conocer qué tipo concreto de combinación se le está ofreciendo.

\subsubsection{Villar Rodriguez, ed. (1999): Diccionario de la lengua española}

En la brevísima Advertencia (p. viII) con la que se abre el Diccionario de la lengua española $(D L E)$, en la que se da cuenta de los criterios que se han aplicado para la ordenación de las entradas, se afirma que

Detrás de las acepciones generales de las entradas van los términos compuestos $\mathrm{y}$, a continuación las frases hechas y las locuciones, cada uno con su orden alfabético interno. 
Si nos detenemos en los ejemplos que se han seleccionado para aclarar la Organización léxica de las entradas del diccionario (p. IX), en el espacio reservado para ejemplificar la inclusión de los términos compuestos ${ }^{39}$ en el diccionario se incluye la locución nominal agujero negro.

La consulta de algunas de las entradas del DLE nos ha permitido comprobar que en el lugar destinado a los términos compuestos se incluyen, además de las locuciones nominales, otras unidades léxicas que corresponden a los compuestos sintagmáticos (león marino) y a las colocaciones (dinero sucio).

dinero [...]||dinero sucio El que se gana con actividades ilegales: su fortuna es toda de dinero sucio ganado en casinos ilegales.

Otros mecanismos utilizados en el diccionario para dar cuenta de las colocaciones son:

a) A través de los ejemplos. Este es el caso de locamente enamorado:

locamente adv. m. [...] || Excesivamente, sin prudencia ni moderación: está locamente enamorado.

b) En la definición del lema. Se presenta así la colocación asestar un golpe:

asestar tr. Dirigir o descargar un proyectil o un golpe contra un objetivo.

\subsubsection{A. Sánchez Pérez, dir. (2001): Gran diccionario de uso del español actual}

En el apartado $I V$. Ilustración de la estructura de cada voz e información que contiene (pp. 12-14), se hace una mención expresa a las «voces de dos o más términos cuyo núcleo es el término alfabetizado» (p. 14). En estos casos, el Gran diccionario de uso del español actual (GDUEA) resalta al final de un artículo lexicográfico, en un renglón aparte, en negrita y acompañadas de su definición, las voces que están constituidas por dos o más vocablos. Hemos comprobado que en algunas de estas construcciones estamos ante ejemplos claros de colocaciones, en las que la base es el lema alfabetizado (error craso, error de bulto, error garrafal).

e.rror $[\ldots]$

Error craso/ de bulto/ garrafal, error de mucha importancia o gravedad: La decisión de trasladar el cuadro fue un error garrafal.

Siguiendo este mismo procedimiento también se incluyen en el diccionario numerosos ejemplos de locuciones nominales (bomba de relojería, tiempo muerto) y compuestos sintagmáticos (falda pantalón, centro comercial).

Además del espacio reservado para las voces de dos o más términos, otros recursos empleados por el GDUEA para recoger colocaciones son:

a) En el lugar del artículo lexicográfico reservado a las locuciones. De esta manera se presenta la colocación dejar frío: ${ }^{40}$

\footnotetext{
${ }^{39}$ Más adelante, en la p. XII, se presentan los Símbolos utilizados en el diccionario y se habla de conceptos dobles para hacer referencia a las construcciones que previamente se habían denominado términos compuestos.

${ }^{40}$ Esta colocación responde al tipo V + Adj., recogido por Koike (2001: 54-55) y Penadés Martínez (2001: 70).
} 
frí•o, -ía [...] Loc [...] Dejar frío a alguien [...] 2, dejar una cosa (noticia, suceso) tan impresionado a alguien que no sabe cómo reaccionar ni qué decir: La noticia del accidente y de su muerte me dejó frío.

b) En el ejemplo que sirve para aclarar una acepción concreta. Así se introduce la colocación batalla feroz:

fe·roz [...] 3. Se aplica a todo aquello que causa terror, destrozo y daños, que es cruel o muestra crueldad: Una feroz batalla.

c) En la propia definición de una acepción. De acuerdo con este mecanismo, encontramos la colocación medida drástica:

drás·ti·co, -ca [...] 1 Se aplica a cualquier regla, medida o condición que resulta clara, enégica o que afecta a lo esencial o a lo más importante de algo: Las autoridades dictaron medidas drásticas.

\subsubsection{Otros diccionarios}

En primer lugar, vamos a ocuparnos en este apartado de aquellos diccionarios cuyas páginas introductorias no sólo no realizan ninguna mención al concepto de colocación, sino que además no hacen referencia a ningún tipo de unidades bajo las cuales pueda recogerse en la microestructura algún caso de colocaciones. ${ }^{41}$ Ello no impide, no obstante, que se distribuyan ejemplos de colocaciones a lo largo de la microestructura de los diferentes diccionarios examinados gracias a:

a) La propia definición de un lema. Se introducen de esta manera las colocaciones rescindir un contrato, ramo de flores:

RESCINDIR. tr. Dejar sin efecto un contrato, obligación, etc. (DEM).

ramo $s . m$. 1. Conjunto natural o artificial de flores o ramas $(D L)$.

b) El espacio destinado a dar cuenta de otros tipos de unidades fraseológicas. Bajo la etiqueta fr. (frase) se presenta dar bombo:

вомво. [...] || Dar вомBo fr. fig. y fam. Elogiar con exageración (DEM).

c) Los ejemplos propuestos para aclarar la información ofrecida de un lema. Con bastante frecuencia se presentan en el CLAVE numerosas colocaciones siguiendo este procedimiento. Este es el caso de la colocación dar un garbeo:

garbeo s. m. col. Paseo: Voy a dar un garbeo por la plaza.

d) Mediante el contorno. Gracias a la información contenida en el contorno, de nuevo el $C L A V E$ se convierte en una interesante fuente de información colocacional. Así documentamos la colocación entablar una conversación:

entablar v. Referido esp. a una conversación, a una relación o una disputa, iniciarlas o darles comienzo. 
En segundo lugar, queremos dirigir nuestra atención a REDES. Diccionario combinatorio del español contemporáneo, dirigido por Bosque y publicado en 2004. Aunque no se trate de un diccionario general de la lengua, nos parece que la singularidad de esta obra, al ofrecer los contextos en los que se pueden utilizar las palabras, también merece nuestra atención.

En la Presentación con la que se inicia este diccionario combinatorio, ${ }^{42}$ Bosque afirma que no estamos ante un diccionario de colocaciones, si bien adelanta que en la sección 11 del apartado dedicado a Combinatoria y significación. Algunas reflexiones se ocupará de las «coincidencias y divergencias» (p. XXII) que existen entre los diccionarios de colocaciones y $R E D E S$. El título con el que aparece la sección 11 es Colocaciones y restricciones léxicas. La dirección de la búsqueda (pp. CLII-CLVIII) y en ella se afirma que

Aun en el caso hipotético de que REDES fuera un diccionario de colocaciones (lo que puede aceptarse o no independientemente de cuál sea mi postura particular sobre este asunto), es claro que el punto de vista sobre la combinatoria léxica que se defiende en esta obra no es análogo al que sustentan los diccionarios de colocaciones existentes, entre ellos los que menciono en el siglario que aparece al final de este trabajo. En mi opinión no se trata de una diferencia lexicográfica, sino de una diferencia conceptual. REDES coincide con todos los diccionarios a los que me refiero en presentar información combinatoria, pero opta por una concepción diferente de los mecanismos semánticos que la sustentan (p. CLIII). ${ }^{43}$

A partir de la lectura de este párrafo y de la consulta de otras partes del diccionario, así como de la concepción particular que Bosque tiene del término colocación, adscrito a una clase específica de relaciones de selección léxica (2004: CLIV), podemos decir que REDES, al ser un material representativo de las restricciones semánticas que las palabras se otorgan unas a otras y describir la forma en que los predicados seleccionan a sus argumentos, no puede considerarse un diccionario exclusivo de colocaciones, aunque sí dé cabida en las listas de restricciones léxicas que presenta a construcciones que pueden recogerse dentro del concepto de colocación, dependiendo de la orientación que estemos siguiendo. ${ }^{44} \mathrm{~A}$ modo de ejemplo, en la microestructura de REDES documentamos colocaciones originadas a partir de la frecuencia de coaparición de dos unidades léxicas (clavar la mirada $)^{45}$, colocaciones que se han creado a

${ }^{41}$ Los diccionarios examinados son los siguientes: Diccionario del español moderno (DEM), 1960; Diccionario de la lengua (DL), 1994; Clave. Diccionario de uso del español actual (CLAVE), 1997.

${ }^{42}$ La obra está dirigida «a los profesionales del idioma y a los hablantes que se preocupan por su uso; a los que desean indagar en la naturaleza de las combinaciones y a los que simplemente quieren conocerlas, aprenderlas, practicarlas, aplicarlas, traducirlas, alterarlas o recrearse en su contemplación» (p. XIX).

${ }^{43}$ Los siete diccionarios de colocaciones citados por Bosque (CLIII) pueden agruparse según se vinculen con uno de estos dos conceptos de colocación: a) una colocación tiene que ver con la frecuencia de coaparición de dos unidades léxicas y b) la colocación resulta de dar forma léxica a una relación semántica que puede describirse formalmente. De los diccionarios mencionados, sólo hay dos para la lengua española: el Diccionario euléxico para expresarse con estilo y rigor, Barcelona, Juventud, 2000, de J. Borneu, y el Diccionario de colocaciones del español $(\mathrm{DiCE})$, proyecto dirigido por Alonso Ramos. El diccionario de Borneu estaría dentro de la primera orientación y el diccionario de Alonso Ramos dentro de la segunda.

${ }^{44}$ Higueras García (2005: 485-486) ha destacado la importancia de REDES como fuente de información colocacional para los aprendices de E/LE, si bien no sean las colocaciones las unidades de interés y de análisis de este diccionario.

${ }^{45}$ En REDES aparece clavar la mirada con las marcas de frecuencia ++ , lo que nos permite interpretar que estamos ante una combinación sumamente frecuente. 
partir de una conexión semántica entre palabras marcada por una función léxica (hacer un favor: Oper 1 (favor) $=$ hacer [un ]), o colocaciones que son un claro ejemplo de combinatoria léxica restringida (encapotarse el cielo).

Toda la información que acabamos de exponer nos sirve para concluir, a propósito de las alusiones que $R E D E S$ hace en sus páginas introductorias al tratamiento e inclusión del concepto de colocación en su microestructura, que estamos ante un diccionario que dedica un apartado específico a explicar qué vinculaciones y qué diferencias pueden establecerse entre la naturaleza de la información combinatoria incluida en su microestructura y algunas concepciones particulares del concepto de colocación, específicamente las relacionadas con la frecuente coaparición de dos unidades léxicas y la conexión semántica que viene definida por una función léxica entre una base y un colocativo.

\subsection{DiCCIONARIOS DIDÁCTICOS}

\subsubsection{Diccionario Esencial Santillana de la Lengua Española (1991) ${ }^{46}$}

En las Indicaciones de uso (p. IX), se afirma en el apartado dedicado a las Remisiones que

si la remisión se dirige a un término compuesto o a una locución, se usa la fórmula «Véase...». Ejemplos:

gallina (...) || 3. carne (o piel) de gallina Véase carne.

apear (...) $\|$ Loc. (...) apearse del burro Véase burro.

El análisis de los dos ejemplos que se utilizan para aclarar lo que en el Diccionario Esencial Santillana de la Lengua Española (DESLE) se entiende por términos compuestos (carne de gallina y piel de gallina), nos permite afirmar que estamos ante dos casos de colocaciones, en los que carne y piel funcionan como la base de la colocación y de gallina como el colocativo. Este hecho nos lleva a pensar que bajo la denominación formas compuestas este diccionario estaría incluyendo también el concepto de colocación. Asimismo, nuestra afirmación parece estar avalada por los ejemplos que se proponen en la p. X para aclarar cómo se distribuyen los términos compuestos en la entrada del diccionario, pues entre ellos se recoge la colocación abogado de oficio:

abogado, da [...] || 4. abogado de oficio El designado por la ley para defender a las personas pobres desde el punto de vista legal.

La consulta de la microestructura del DESLE muestra que bajo el marbete término compuesto, además de las colocaciones, se agrupan otros dos tipos de combinaciones léxicas diferentes: los compuestos sintagmáticos (caja negra, caja registradora) y las locuciones nominales (cabeza de turco, caldo de cultivo). Los términos compuestos se presentan siempre numerados y precedidos por $\|$.

Además de recogerse colocaciones en el espacio destinado a las formas compuestas, en este diccionario también se recolectan gracias a:

a) Los ejemplos concretos de colocaciones que se ofrecen para aclarar la información contenida en la definición y en otras indicaciones. Así se presenta la colocación tomar apuntes:

${ }^{46}$ Se trata de un diccionario dirigido principalmente al «estudiante de nuestros días» (p. VII). 
apunte $s . m$. 1. Nota por escrito, resumen o extracto que se hace de algo. Se usa mucho en $p l$ : tomar apuntes.

Hay casos en los que los ejemplos sirven para contextualizar el lema. De acuerdo con este procedimiento, nos encontramos con la colocación rogar encarecidamente:

encarecidamente $a d v . m$. Con encarecimiento o insistencia: Me rogó encarecidamente que fuera.

b) La definición que se facilita de un lema. La colocación zanjar una discusión se localiza de esta manera:

zanjar v. tr. 1. Terminar un asunto, problema, discusión, etc.

5.2.2. F. Moreno Fernández, coord. (1995): Diccionario para la enseñanza de la lengua española (DiPELE) $)^{47}$

En la Guía para consultar este diccionario que aparece en las guardas del DiPELE, se utiliza el término subacepción para recoger las construcciones eclipse lunar y eclipse solar que aparecen bajo la entrada eclipse:

e•clip·se $\mid$ eklípse $\mathbf{1} \boldsymbol{m}$. Ocultación de un cuerpo celeste por la interposición de otro: se fueron al campo a ver el $\sim$; lunar, el que se produce cuando la Tierra se interpone entre el Sol y la Luna: el otro día presenciamos un lunar; solar, el que se produce cuando la Luna se interpone entre la Tierra y el Sol: el próximo lunes habrá un $\sim$ solar. ${ }^{48}$

La consulta de la microestructura del diccionario nos permite comprobar que será justamente en el espacio reservado para dar cuenta de las subacepciones de un lema donde vamos a encontrar numerosas construcciones colocacionales. Siguiendo este procedimiento, se registra en este diccionario la colocación nariz aguileña:

na·riz [...] aguileña, la que es curva y sale excesivamente de la cara, y que parece el pico de un águila: la aguileña no es del gusto de muchas personas.

Más adelante, en el espacio reservado para explicar la «Selección y ordenación de las entradas» (pp. XI-XII) se recoge que

En lo que se refiere a las formas compuestas, solamente las que se escriben como una sola palabra o con guión constituyen entrada. Las demás aparecen dentro de la entrada correspondiente a uno de los elementos en composición o como locución en la parte de la entrada destinada a la fraseología. Las formas compuestas que designan clases de otros elementos (p. e., guardia civil, de guardia) aparecen como subacepciones sin numerar, detrás de la definición correspondiente (p. XI).

${ }^{47}$ Este diccionario está dirigido a estudiantes de español que desean aprender o perfeccionar la lengua española, bien como primera lengua o bien como segunda lengua.

${ }^{48}$ Reproducimos el texto tal y como aparece en las guardas del diccionario. Por esta razón no se ofrecen las páginas. 
Tras la lectura de este párrafo y de la posterior revisión de algunos artículos lexicográficos, hemos podido verificar que los compuestos sintagmáticos (guardia civil, caja fuerte), las locuciones (talón de Aquiles) y las colocaciones (hambre canina) se presentan en el mismo espacio -el destinado a las subacepciones de un lema-y sin ningún tipo de marcación o separación entre ellos.

ham·bre [...] $\mathbf{1} \boldsymbol{f}$. Gana y necesidad de comer: tengo $\sim$, ¿podemos comer ya?; hoy he pasado mucha $\sim$; canina, fig., deseo muy fuerte de comer: con la gripe no he comido y ahora tengo una $\sim$ canina.

Además de incorporar colocaciones en el espacio destinado a anotar las subacepciones de un lema, en este diccionario se puede rastrear la presencia de las colocaciones en:

a) Los ejemplos que aclaran una acepción determinada. De acuerdo con este procedimiento, se presenta la colocación entablar una relación:

en·ta.blar [...] 2 Disponer o preparar; dar comienzo a un asunto o negocio: la directora de la empresa ha entablado relaciones con una empresa extranjera del mismo ramo.

b) La propia definición del lema. A modo de ejemplo, citamos la colocación tableta de chocolate:

ta:ble $\cdot$ ta $[\ldots] \mathbf{1} f$. Trozo de chocolate de forma plana y rectangular.

\subsubsection{J. Gutiérrez Cuadrado, dir. (1996): Diccionario Salamanca de la lengua española} $(\mathrm{DSLE})^{49}$

En el DSLE se utiliza explícitamente el término colocación en su «Introducción». En el apartado dedicado a Objeto y contenido del diccionario Salamanca, se reserva un espacio específico para dar respuesta a esta pregunta: ¿Qué encontrar en el diccionario? (pp. V-VI), donde se afirma que

Además de las palabras generales del léxico actual del español, sin arcaísmos ni dialectalismos, el usuario encontrará [...] muchos ejemplos que aclaran las definiciones, muestran muchas colocaciones habituales y sirven de modelo de construcción sintáctica.

La consulta de los artículos lexicográficos del diccionario nos ha permitido comprobar que, efectivamente, constituyen un número elevado las colocaciones recogidas en los ejemplos que se incluyen. Este es el caso de zanjar una discusión:

zanjar $v$. tr. Resolver <una persona $>$ [un asunto o una dificultad]: Su novia zanjó la discusión con un portazo $[\ldots]$.

La alusión directa a la presencia de las construcciones colocacionales en los ejemplos vuelve a hacerse, por segunda vez, unas páginas más adelante, cuando en el apartado $V$. Ejemplos se dice que

${ }^{49}$ Estamos ante un diccionario dirigido especialmente a los estudiantes que aprenden español y a los profesores que lo enseñan. 
Se tienen en cuenta tanto las posibilidades o nivel de uso, como las colocaciones o contextos. En muchos casos el ejemplo no es una frase completa, sino una construcción que indica las colocaciones más frecuentes (p. XI).

En la microestructura del DSLE es amplio el número de ejemplos destinados a dar cuenta, sin ningún contexto, de las colocaciones que tienen como base un sustantivo. Esta manera es la utilizada para recoger la colocación éxito clamoroso:

clamoroso , sa [...] 2 Que es extraordinario o mayor de lo acostumbrado: éxito clamoroso, recibimiento clamoroso, un fracaso clamoroso.

Especialmente significativos resultan también otros párrafos pues, aunque no se habla de manera explícita de colocaciones, la ulterior consulta del diccionario pone de manifiesto que de manera indirecta se está haciendo alusión en ellos al concepto de colocación. En este sentido, en el apartado $I V$. Definiciones (p. XI), a propósito de las informaciones que acompañan las definiciones de los verbos y adjetivos, se dice que se incluyen datos de índole sintáctica para ayudar al usuario a elaborar frases correctas. En relación a los verbos, se afirma que «En todas las definiciones aparece marcado el tipo de sujeto con un paréntesis en águlo $<>$. Los complementos se marcan con los corchetes [ ]» (p. XI).

Esto quiere decir que en muchos casos la información adicional recogida en los paréntesis y en los corchetes sirve para construir una verdadera colocación. Así son recogidas en el diccionario muchas colocaciones formadas por sustantivo (sujeto) + verbo: correr un rumor, y verbo + sustantivo (objeto): asestar un golpe:

correr [...] 6 Pasar < una noticia o un rumor> de unas personas a otras: El rumor de su compromiso corrió entre la gente con gran rapidez, y a la media hora ya lo sabía toda la fábrica.

asestar [...] Dar <una persona > [un golpe, un tiro o una puñalada].

En cuanto a los adjetivos, se concluye que

Utilizan los corchetes [ ] para marcar el grupo de sustantivos al que pueden aplicarse. Unas veces se utilizan entre corchetes sustantivos genéricos que definen el conjunto al que se puede aplicar el adjetivo. Así [plata], [persona]. En otros casos, aparecen entre corchetes uno o varios sustantivos que sirven de ejemplos de todo el grupo. No es raro tampoco, como puede comprobarse por los ejemplos, que entre paréntesis aparezcan los únicos sustantivos que acompañan a un adjetivo determinado (p. XI).

La revisión del diccionario evidencia que son muchas las colocaciones que responden al tipo adjetivo + sustantivo que se ofrecen en la microestructura del diccionario gracias a la inclusión de las bases, entre corchetes [], en la definición ofrecida para el colocativo. La colocación discusión encarnizada es un claro ejemplo de este procedimiento:

encarnizado, da $a d j .1$ (ser / estar; antepuesto / pospuesto) [Batalla, discusión] que se hace con apasionamiento y violencia: La lucha fue encarnizada. La encarnizada batalla no tuvo vencedores. 
Y para finalizar nuestros comentarios acerca del DSLE, diremos que bajo la denominación locuciones de acepción se recogen también construcciones colocacionales, tal y como se desprende de la consulta de la microestructura del diccionario. En el apartado VII. Frases y locuciones (p. XII) se dice que por locuciones de acepción se entienden

Las que aparecen dentro de una acepción numerada. En este caso pueden encontrarse dos tipos:

a) las que equivalen semánticamente a la suma de sus dos miembros y no se definen [...];

b) las que no equivalen a sus miembros y deben definirse [...] (p. XII).

Tras la consulta del diccionario, podemos concluir que dentro de las locuciones de acepción del tipo a) se incluyen las colocaciones (muerte natural, muerte violenta), mientras que en las locuciones de acepción del tipo b) se colectan sin diferenciarse los compuestos sintagmáticos (oso hormiguero, avión comercial, vía rápida) y las locuciones nominales (diente de león):

muerte $s . f$. 1 Final de la vida: La muerte nos espera a todos. Sin. Defunción, fallecimiento. natural. súbita. violenta. dulce Muerte sin dolor.

\subsubsection{Otros diccionarios didácticos}

Vamos a ocuparnos también de aquellos otros diccionarios que, independientemente de que en sus páginas introductorias no hagan ninguna mención al concepto de colocación y no incluyan referencia alguna sobre algún tipo de unidades bajo las cuales pueda recogerse en la microestructura algún caso de colocaciones, ofrecen una interesante información colocacional por medio de los siguientes mecanismos: ${ }^{50}$

a) La propia definición ofrecida a propósito de un lema. Se recogen así las colocaciones rebanada de pan o ristra de ajos:

rebanada $[\ldots]$ Trozo fino de pan $(D D E E) .{ }^{51}$

ristra $[\ldots]$ 1. Trenza de ajos, cebollas, etc. $(D A L) .^{52}$

b) La información sintáctica presentada para una acepción determinada. Este es el caso de dar el espectáculo:

espectáculo 3 Lo que causa gran extrañeza o escándalo: Con tantos gritos, disteis un buen espectáculo en medio de la calle. ISINT. La acepción 3 se usa más con el verbo dar (DDEI). ${ }^{53}$

c) Los ejemplos. Ofrecemos como ilustración las colocaciones despuntar el día, hambre canina, descubrir el pastel, dar el cambiazo o tableta de chocolate:

${ }^{50}$ Los diccionarios analizados son los siguientes: Diccionario Anaya de la Lengua (DAL), 1979; Diccionario básico de la lengua española (DBLE), 1987; Gran diccionario de la lengua española (GDLE), 1987; Larousse júnior. Diccionario ciclo inicial (LJDCI), 1992; Larousse escolar. Diccionario de la lengua española (LEDLE), 1993; Diccionario didáctico de español intermedio (DDEI), 1993; Diccionario didáctico de español elemental (DDEE), 1994.

${ }^{51}$ Este diccionario está redactado para niños en edad escolar.

${ }^{52} \mathrm{Se}$ trata de un diccionario destinado a escolares.

${ }^{53} \mathrm{El}$ diccionario está recomendado para estudiantes que tienen entre doce y dieciséis años. 
despuntar [...] 3 Empezar a aparecer la luz del día: Me despierto todas las mañanas al despuntar el día $(D D E E)$.

canino, a [...] hambre canina 3. Después de una excursión de ocho horas sintieron un hambre canina (= apetito insaciable) $\left(\right.$ LEDLE). ${ }^{54}$

pastel [...] 5 col. Convenio o plan secretos realizados con malos fines: La policía descubrió el pastel y los metió a todos en la cárcel (DDEI).

cam·bia·zo [...] Sustitución de una cosa por otra: Te han dado el cambiazo: este diamante es falso $(G D L E){ }^{55}$

tableta s. f. Juan se comió la tableta de chocolate antes que las galletas (= la pastilla de chocolate). $(L J D C I) .{ }^{56}$

d) El espacio destinado a dar cuenta de diferentes unidades fraseológicas. Bajo el marbete expresión encontramos la colocación dar calabazas en el DDEE:

calabaza [...] 3 [expresión] dar calabazas Decir que no se quiere tener una relación de amor con quien lo ha pedido: No me atrevo a declararme a esa chica por miedo a que me dé calabazas.

En otros diccionarios la colocación se halla en el espacio reservado a las locuciones. Este es el caso de decir pestes y dirigir el cotarro:

peste [...] ||decir pestes de alguien; col. Hablar mal de él: Dice pestes de su jefe, porque no lo ha ascendido $(D D E I) .57$

co·tar·rro $[\ldots]$ LOC Dirigir el cotarro, mandar o controlar un asunto $(D B L E) .{ }^{58}$

e) El contorno de la definición. Así se incluyen las colocaciones dolor agudo, momento crucial o dar palique:

agudo, -a [...] 5. fig. Dícese de un dolor vivo y fuerte, o de la enfermedad que aparece bruscamente y con violencia, pero de corta duración $(D A L)$.

crucial adj. Referido esp. a un momento o a un punto, que son decisivos o muy importantes porque condicionan el desarrollo de algo (DDEI).

pa·li·que [...] (Estar de/Dar) Conversación de poca importancia $(D B L E)$.

\subsection{DiCCIONARIO FRASEOLÓGICOS}

\subsubsection{F. Varela y H. Kubarth (1994): Diccionario fraseológico del español moderno (DFEM)}

${ }^{54}$ Estamos ante un diccionario escolar en el que se ofrecen las colocaciones en los ejemplos con los que se contextualiza el lema y se redacta, además, una paráfrasis definitoria de esa construcción colocacional.

55 Este diccionario tiene como «destinatarios prioritarios» (p. v) a los estudiantes extranjeros y a los estudiantes medios de español, además de a los profesores de lengua española.

${ }^{56} \mathrm{El}$ diccionario está pensado para niños y en él no se explican las palabras con definiciones, sino que se proporciona después de cada entrada una frase en la que se utiliza el lema. También se añade una paráfrasis del significado con el que se está utilizando el lema.

${ }^{57}$ La colocación decir pestes aparece marcada como una locución al estar precedida por $\|$.

${ }^{58}$ Este diccionario tiene como destinatarios principales el estudiante medio de español, así como el estudiante extranjero y los profesores de lengua española. 
En la Introducción (pp. VII-XIV) del DFEM no aparece el término colocación ni ninguna referencia al contenido que recoge este concepto cuando los autores dan cuenta de las unidades fraseológicas que se han recopilado en el diccionario dentro de uno de estos tres grupos: 1 . locuciones (de uvas a peras, todo dios), 2. complejos fraseológicos con casillas vacías (VERBO + que (te/le) + VERBO: habla que te habla, dale que dale) y 3. expresiones (y listo, ; a mí plin!) que facilitan el funcionamiento de la comunicación y la interacción social. La lectura previa de la relación de los tipos de unidades fraseológicas incluidas por los autores en el contenido del diccionario lleva a pensar que las colocaciones han sido excluidas de este diccionario fraseológico; sin embargo, la consulta posterior de su microestructura nos obliga a considerar, siguiendo a Penadés Martínez (2001), ${ }^{59}$ que algunas de las locuciones verbales de las que da cuenta el diccionario podrían catalogarse como verdaderas colocaciones. Este es el caso, entre otras, de la combinación dar un estirón, en la que el sustantivo estirón, según el $D U E^{60}$ y el $D E A,{ }^{61}$ para esa acepción concreta puede construirse con el verbo dar, independientemente de que ese sustantivo mantenga esa misma acepción cuando aparezca en el discurso en compañía o no de otros verbos distintos de dar. Además, si dar un estirón fuera una locución verbal, su definición debería realizarse sin contener el significado de uno de sus componentes; sin embargo, el $D F E M$ la define como «Crecer mucho en poco tiempo». Por lo tanto, en virtud de la información proporcionada por el $D U E$ y el $D E A$, podemos considerar la construcción citada como colocación y excluirla de la nómina de locuciones verbales presentadas por el $D F E M$.

\subsubsection{Seco, dir. (2004): Diccionario fraseológico documentado del español actual (DFDEA)}

En el espacio dedicado al Contenido del Diccionario (pp. XVI-XVIII), que aparece en Sobre este Diccionario (pp. XI-XVIII), se especifican explícitamente qué clases de unidades fraseológicas van a documentarse en el $D F D E A$. Además de las locuciones en sentido estricto (abogado de causas perdidas, a ojo de buen cubero, hasta más ver, etc.), ${ }^{62}$ las fórmulas oracionales (no hay más cera que la que arde, en todas partes cuecen habas, cuéntaselo a tu abuela, etc.) ${ }^{63} \mathrm{y}$ las fórmulas expletivas ( $y$ demás, ni gaitas, ni historias), ${ }^{64}$ caben también en este dic-

${ }^{59}$ La autora ha analizado para la letra D un total de 104 unidades fraseológicas consideradas por el $D F E M$ como locuciones verbales. A partir de la información que proporcionan algunos diccionarios generales de la lengua y de la descripción suministrada por algunos investigadores sobre el concepto de colocación, Penadés Martínez concluye que las locuciones mencionadas podrían ser analizadas como auténticas colocaciones. Teniendo en cuenta la categoría de los colocados, las colocaciones seleccionadas en el corpus examinado corresponderían a uno de los siguientes tipos: $\mathrm{V}+\mathrm{N}($ dar coba $), \mathrm{V}+\operatorname{det}+\mathrm{N}$ (darse la gran vida), $\mathrm{V}+$ prep. $+\mathrm{N}$ (dejarse de cuentos), $\mathrm{V}+\mathrm{Adj}($ dejar frío), colocaciones con estructuras comparativas (dormir como un tronco) o V + Adv (dejar atrás).

${ }^{60}$ «estirón («Dar, Pegar un»). 2 Crecimiento brusco o rápido en estatura».

${ }^{61}$ «estirón $m 1$ Crecimiento rápido o brusco [de una pers.] Gralm en la constr DAR (o PEGAR) UN (o EL) . Tb fig.».

${ }^{62}$ Se trata de «agrupaciones más o menos fijas de palabras, conjuntos que tienen su función gramatical (nombre, pronombre, adjetivo, verbo, adverbio, preposición, etc.) como la tienen las palabras individuales; y que también, como si fuesen palabras individuales, tienen un valor estable propio que no es la suma de los de sus componentes» (p. XVI).

${ }^{63}$ Estamos ante «enunciados de forma fija y sentido peculiar que -a diferencia de las locuciones- no están integrados dentro de una oración funcionando en ella como palabras (nombre, verbo, etc.), sino que funcionan como oraciones por sí mismas» (p. XVIII).

${ }^{64}$ Estas unidades fraseológicas están «prácticamente vacías de significado. Aparecen al término de la frase, y solo desempeñan, unas, un papel de simple relleno con que se remata el enunciado [...]; y otras, el papel de refuerzo enfático de una negación o un rechazo [...]. Unas y otras son propias de la lengua hablada» (p. XVII). 
cionario las construcciones de sentido comparativo (más largo que un día sin pan, llover más que cuando enterraron a Zafra) y las colocaciones (prestar atención, dar corte). Estos dos últimos tipos de combinaciones fraseológicas, que aparecen bajo el marbete común de locuciones en sentido amplio, son, según los autores del DFDEA, combinaciones que comparten algunos rasgos comunes con las locuciones estrictas. ${ }^{65}$ Por lo que se refiere a las colocaciones, unidades objeto de nuestro interés, se afirma que estamos ante «asociaciones muy habituales»o «fijas» de un nombre con un verbo, de un verbo con un adverbio, etc., en las que uno de sus componentes mantiene su significado, y cuyo comportamiento en el discurso las aproxima a las locuciones estrictas, al aparecer siempre como un bloque unitario. Los autores del diccionario insisten en que solamente se han registrado aquellas colocaciones que son de uso muy frecuente y que se caracterizan también por tener una consolidada fijeza en la lengua.

La posterior consulta de la microestructura del DFDEA nos permite comprobar que todas las unidades fraseológicas contenidas en el diccionario aparecen adscritas, después de la presentación del lema, a alguno de los tipos de fraseologismos citados, aunque para el caso concreto de las colocaciones formadas por un verbo la etiqueta utilizada $-v$ (locución verbal) - provoca que no aparezcan diferenciadas, por ejemplo, las colocaciones darle la ventolera o dirigir el cotarro de las locuciones verbales no pegar ni con cola o ir con la copla. De la misma manera, tampoco las colocaciones del tipo Sust + Adj (memoria de elefante o lujo asiático) se distinguen de las locuciones nominales (edad de merecer o demonios familiares), pues todas ellas aparecen marcadas en el diccionario como locuciones nominales. ${ }^{66}$

\section{CONCLUSIONES}

Con relación a los diccionarios generales, tras nuestro análisis extraemos las siguientes conclusiones:

1. El $D E A$ es el único diccionario en el que sus autores emplean explícitamente en las páginas introductorias el término colocación (o construcción preferente), a la hora de referirse a la relación sintáctica que se crea entre el lema y otras palabras para llegar a una acepción concreta.

2. El resto de denominaciones que los diccionarios examinados manejan en las que parecen estar incluyendo el concepto de colocación se reducen a dos: la de expresiones pluriverbales para las combinaciones de adjetivo + adverbio, nombre + adjetivo y verbo + adverbio, en el DUE; y la de forma compleja para el tipo sustantivo + adjetivo, en la última edición del diccionario académico.

3. Aunque en muchas ocasiones los diccionarios generales no hagan una referencia expresa al concepto colocación, implícitamente sí lo están manejando para:

- El tipo sustantivo + adjetivo cuando se alude a: 1) las acepciones concretas que tiene el sustantivo si aparece modificado por una palabra que se comporta como un adjetivo $(D M I L E), 2)$ las subacepciones dentro de un lema $(D P L E)$ y 3$)$ la presen-

${ }^{65}$ A propósito de las construcciones de sentido comparativo se insiste en el hecho de que el término de comparación es fijo con relación al antecedente. Estas unidades van iniciadas por como o más que, o confeccionadas de acuerdo al siguiente modelo: más + adjetivo (u otra clase de palabra) + que.

${ }^{66}$ Memoria de elefante y edad de merecer aparecen seguidas de la abreviatura $f$ (locución nominal femenina) y lujo asiático y demonios familiares de $m$ (locución nominal masculina). 
tación entre corchetes de los elementos habituales del contorno de algunos de los lemas en una acepción determinada $(D E A)$.

- El tipo verbo + sustantivo (objeto) y sustantivo (sujeto) + verbo en las aclaraciones de tipo gramatical que hace el $D U E$ sobre la vinculación de algunos verbos con ciertos sustantivos para formar frases. Asimismo, este diccionario vuelve a hacer alusión al concepto de colocación para el tipo verbo + sustantivo(objeto) a través de algunos de los ejemplos que propone para aclarar lo que entiende por equivalentes pluriverbales frente a expresiones monoverbales.

4. La lectura de las páginas introductorias de los diccionarios generales y la consulta de su microestructura evidencia que bajo un determinado marbete los diccionarios están recogiendo combinaciones léxicas diferentes: a) en la última edición del diccionario de la Real Academia se utiliza la denominación forma compleja para abarcar el concepto de colocación, locución nominal y compuesto sintagmático, así como diferentes tipos de unidades fraseológicas; b) el $D U E$ presenta colocaciones en el espacio reservado a las frases y modismos usuales; c) el DPLE y el GDUEA agrupan también algunos ejemplos de colocaciones en el apartado final del artículo lexicográfico destinado a las locuciones; d) el DLE recoge como términos compuestos algunos casos de colocaciones, compuestos sintagmáticos y locuciones nominales; e) el DEM documenta colocaciones bajo el marbete frases. En este apartado se incluyen también otros tipos de unidades fraseológicas.

5. En ningún diccionario (ni en el espacio en el que un artículo lexicográfico recoge las combinaciones usuales de un sustantivo con otras clases de palabras $-D R A E$, $D M I L E$ - ni en la parte del artículo lexicográfico en la que se recolectan las voces de dos o más términos - GDUEA-, ni en el apartado destinado a las frases y modismos usuales de la lengua - $D U E, D E M-$ ) se han incluido las colocaciones, las locuciones nominales y los compuestos sintagmáticos con algún tipo de marca que permita distinguirlos. La ordenación de estos tres tipos de combinaciones, cuando aparecen juntas, responde a criterios simplemente alfabéticos. El único diccionario en el que se separan claramente en sus páginas introductorias las referencias al concepto de colocación de las alusiones a las unidades léxicas compuestas o a las locuciones es el $D E A$, aunque después la disposición de las tres combinaciones en la microestructura no informe al lector sobre el estatus de cada una de ellas.

6. Los procedimientos que utilizan los diccionarios generales para dar cuenta de una colocación en su microestructura son diversos y no están presentes con la misma intensidad en todas las obras. La información colocacional se ha hecho patente gracias a las propias definiciones ( $D R A E, G D U E A, D U E, D M I L E, D L E, D P L E, D E M, D L)$, las acepciones y subacepciones del lema $(D E A)$, los ejemplos que aclaran y ejemplifican una definición o una acepción (DRAE, DUE, GDUEA, DMILE, DLE, CLAVE), el contorno (DUE, DEA, DMILE, DPLE, CLAVE), las remisiones que se realizan en el artículo lexicográfico $(D U E)$, las citas empleadas $(D E A)$, los sinónimos utilizados para las definiciones $(D E A)$, los indicadores enlace frecuente, enlace muy frecuente, expresión muy frec. con los que aparecen marcadas algunas combinaciones léxicas (DUE), los términos equivalentes que se listan para algunos lemas y las construcciones recogidas en los apartados específicos destinados a modismos usuales $(D U E)$, locuciones (DPLE, GDUEA), voces de dos o más términos (GDUEA) y frases $(D E M)$. 
En cuanto a los diccionarios didácticos, el estudio que hemos realizado pone de manifiesto que:

1. El único diccionario en el que se utiliza expresamente el término colocación en sus páginas introductorias es el DSLE. Y se emplea para hablar de las colocaciones habituales contextualizadas que muestran muchos de los ejemplos contenidos en el diccionario, así como de las colocaciones, sin ningún contexto, que se ofrecen como ejemplo. Otra mención directa a algunos ejemplos de colocaciones que realiza el diccionario la hace mediante el empleo del término locuciones de acepción, aplicado concretamente a las construcciones composicionales, es decir, aquellas cuyo significado se desprende de la suma del significado de sus componentes. Y la última referencia a la inclusión de información colocacional en el diccionario se manifiesta cuando se aclara al lector que se ofrecen para los verbos el tipo de sujeto y los complementos con los que aparecen, y para los adjetivos los sustantivos a los que pueden aplicarse.

2. Aunque el resto de diccionarios examinados no haga alusión en sus páginas introductorias al concepto de colocación directamente, sin embargo, son varias las colocaciones con las que intentan aclarar la distribución de los términos compuestos (DESLE) o de las subacepciones (DiPELE) dentro del diccionario. En los dos diccionarios mencionados, además de las colocaciones, también se listan ejemplos de compuestos sitagmáticos y locuciones en el mismo espacio, sin ninguna marcación específica para diferenciarlos. Con relación a este aspecto, el DSLE tiene un comportamiento diferente, pues es el único diccionario que distingue en sus páginas introductorias las locuciones de acepción del tipo a (colocaciones) de las locuciones de acepción del tipo b (locuciones nominales y compuestos sintagmáticos).

3. A pesar de no dirigir los diccionarios su atención hacia el fenómeno de las colocaciones en sus páginas introductorias, en la microestructura sí recolectan ejemplos de colocaciones gracias a la información aportada por las definiciones (DESLE, DiPELE, $D D E E, D A L)$, las acepciones (DDEI), las subacepciones (DiPELE), los ejemplos (DESLE, DiPELE, DDEE, LEDLE, DDEI, GDLE, LJDCI) y el contorno ( $D A L$, $D D E I, D B L E)$. A ello tenemos que añadir aquellos casos en los que el espacio dedicado a la fraseología también registra colocaciones bajo el marbete expresión (DDEE) o locución (DDEI, DBLE).

Con relación a los diccionarios fraseológicos examinados, hemos de decir que tanto el $D F E M$ como el DFDEA recogen colocaciones en su microestructura, aunque el primero sin pretenderlo y habiendo rechazado de manera explícita su inclusión. Tan sólo el segundo anuncia directamente en sus páginas introductorias el interés por documentar las colocaciones, pero después no las señala con una marca específica, en consecuencia, no se distinguen de las locuciones en la microestructura. De esta situación se desprende la necesidad de que se elaboren diccionarios de la lengua española sobre colocaciones, y de ahí el valor del proyecto de Alonso Ramos para la elaboración del Diccionario de colocaciones del español (DiCE).

Y por último, queremos finalizar nuestro trabajo insistiendo una vez más en que la introducción tardía del concepto de colocación en la lingüística hispánica y el retraso en realizar estudios sobre colocaciones explican el tratamiento lexicográfico no del todo adecuado e incompleto que los diccionarios han dado a estas unidades, tanto en sus partes introductorias como en la microestructura. Sin embargo, los diccionarios siguen siendo una fuente fundamental para la extracción de información sobre los distintos tipos de colocaciones, los casos concretos en que se manifiestan e, incluso, para su análisis y caracterización. 


\section{ANEXOS 67}

A) Colocaciones documentadas en el lema correspondiente a la base BANCO DE PECES

DUE: banco. [...] 9 Conjunto de peces, por ejemplo sardinas, que van juntos en gran número.

$D E A$ : banco $^{3}[.]$.1 Masa [de peces de una misma especie].

CARNE DE GALLINA

DUE: carne. C. DE GALLINA. (I) Aspecto que toma la piel de las personas, semejante a la de una ave pelada, por efecto del frío o del miedo.

$D E A$ : carne $7 \sim$ de gallina. Aspecto de la piel humana que la hace semejante a la de un ave desplumada y que está causado por el frío o por una emoción, esp. miedo.

CLAVAR LA MIRADA

DUE: mirada. 1 («Atraer; Dirigir; Derramar, Echar, Explayar; Extender, Tender; Detener, Fijar, Posar; Clavar; Levantar»). «Vista». Acción de mirar. Se considera como algo que sale de los ojos y llega al objeto.

CORRER UN RUMOR

$D E A$ : rumor [...] 2 Noticia no confirmada que circula entre la gente. [...] Un rumor circula, estos días, por los Estados Unidos.

DAR BOMBO

DUE: bombo. [...] 3 («Dar»). Elogio exagerado de algo o alguien: 'Lo anuncian con mucho bombo'.

$D E A$ : bombo I [...] 2 (col) Elogio público exagerado. Frec con el $v$ DAR. DAR CALABAZAS

$D E A$ : calabaza I [...] 3 (col.) En pl [...] b) Rechazo de un requirimiento amoroso. Gralm con el v DAR. DAR CORTE

$D E A$ : corte $^{1}[\ldots] 11(\mathrm{col})$. Vergüenza o apuro. Frec con el $v$ DAR.

DAR EL CAMBIAZO

$D E A$ : cambiazo $m$ (col) 2 Hecho de cambiar [1a y 2] de manera fraudulenta. Frec con el $v$ DAR. DAR EL ESPECTÁCULO

DUE: espectáculo. [...] 1 («Dar, Ofrecer, Presentar; Asistir a, Estar en, Presenciar»). Cualquier acción que se ejecuta en público para divertir o recrear; como una sesión de cine, una función de teatro, una exhibición de danza o un partido de fútbol.

$D E A$ : espectáculo [...] 3 Acción escandalosa o inconveniente. Gralm con el $v$ DAR. DAR LA ALARMA

DUE: alarma. [...] 1 («Dar, Sonar la»). Voz o señal con que se avisa un peligro.

$D E A$ : alarma [...] 2 Aviso de peligro. Frec con el $v$ DAR.

DAR PALIQUE

$D E A$ : palique $m$ (col) 1 Conversación intrascendente o de puro entretenimiento. Frec en las constrs ESTAR DE [con alguien], DAR [a alguien].

DAR UN ABRAZO

DUE: abrazo. («Dar»). Acción de abrazar (rodear con los brazos).

${ }^{67} \mathrm{Hemos}$ recurrido a la praxis lexicográfica para decidir que las construcciones que presentamos a continuación son colocaciones, puesto que los autores del $D U E$ y del $D E A$, al considerar que para una acepción determinada de un lema éste ha de aparecer con una unidad léxica concreta, implícitamente están presentando una importantísima información para poder otorgar a la combinación léxica resultante el estatus de colocación. Por otra parte, como se comprobará al leer los dos anexos, una misma colocación aparece en los diccionarios en el lema de la base y en el del colocativo. Ocurre esto, concretamente, en clavar la mirada, correr un rumor, declararse un incendio, diente de leche, entablar una conversación, hombre de bien, odio mortal y zanjar una discusión. 
DAR UN ESTIRÓN

$D U E$ : estirón. («Dar, Pegar un»). 2 Crecimiento brusco o rápido en estatura.

$D E A$ : estirón $m 1$ Crecimiento rápido o brusco [de una pers.] Gralm en la constr DAR (o PEGAR) $\mathrm{UN}(o \mathrm{EL}) \sim . T b f i g$.

DAR UN GARBEO

$D E A$ : garbeo $m$ (col) Acción de garbear ${ }^{1}$. Gralm en la constr DAR(SE) UN . DAR VUELTAS

DUE: vuelta. [...] DAR VUELTAS. (I) (sin complemento). Girar.

$D E A$ : vuelta [...] 2 Movimiento circular completo. Tb fig. Gralm. con el $v$ DAR. DARLE LA VENTOLERA

DUE: ventolera. [...] DARLE a alguien UNA VENTOLERA o LA VENTOLERA DE cierta cosa. Tomar una decisión brusca que se juzga extravagante: 'Le dio la ventolera de marcharse a América'.

$D E A$ : ventolera [...] 2 Capricho o decisión extravagante. Frec en la constr DARLE [a alguien] LA [de algo, o por alguien o algo].

DECIR PESTES

$D U E$ : peste. [...] 5 (en pl.; «Decir, Echar»). Expresiones de queja y crítica contra algo o alguien. DECLARARSE UN INCENDIO

DUE: incendio. 1 («Declararse, Estallar; Provocar; Propagarse; Apagar, Extinguir»). Fuego que destruye algo como un bosque, un edificio o mercancías almacenadas.

DEJAR FRÍO

DUE: frío, -a. [...] DEJAR FRÍo a alguien una cosa. [...] II Dejar pasmado.

$D E A$ : frío -a [...] 7 Sobrecogido o atónito. Normalmente en la constr DEJAR, o QUEDARSE, . DESCUBRIR(SE) EL PASTEL

DUE: pastel. [...] DesCUBRIR[SE] EL PASTEL. Dejar [Quedar] al descubierto algún manejo que se tenía oculto.

DEA: pastel ${ }^{1}[\ldots] 5$ (col) Manejo o asunto que se oculta. Gralm en la constr DESCUBRIRSE EL . DIENTE DE AJO

DUE: diente. [...] DIENTE DE AJO. Cada una de las partes con su envoltura independiente que forman una cabeza de ajo.

$D E A$ : diente [...] 3 Parte de las que, separadas por una envoltura particular, constituyen una cabeza de ajos. Frec $\sim$ DE AJO.

DIENTE DE LECHE

DUE: diente. [...] D. DE LECHE. Nombre dado a los de la primera dentición, que se caen al llegar los niños a cierta edad.

DIRIGIR EL COTARRO:

DEA: $\operatorname{cotarro}^{1}[\ldots]$ Asunto o actividad. Frec con vs como MANEJAR, DOMINAR $o$ DIRIGIR. ENJAMBRE DE ABEJAS

DUE: enjambre. [...] 1 Conjunto de abejas con su reina; particularmente, cuando marchan juntas para formar una colonia nueva.

$D E A$ : enjambre $m 1$ Conjunto de abejas con una reina que salen de una colmena para formar otra nueva.

ENTABLAR UNA CONVERSACIÓN

DUE: conversación. 1 («Entablar, Trabar; Mantener [...]»). «Charla. Coloquio». Acción de conversar.

HACER UN FAVOR

DUE: favor. [...] 1 («Hacer; Derramar, Extender, Repartir, Sembrar; Deber, Tener que agradecer; Corresponder a...»). Ayuda o servicio que se presta a alguien gratuitamente: 'Me ha hecho muchos favores y no sé cómo corresponderle'. 
$D E A$ : favor [...] 1 Acto que se realiza para ayudar o complacer a otro, solo por amabilidad o afecto. Frec con el $v$ HACER $o$, más raro, PRESTAR.

HOMBRE DE BIEN

DUE: hombre. [...] H. DE BIEN. Hombre honrado y recto.

MUERTE NATURAL

DUE: muerte. [...] M. NATURAL. La que sobreviene por enfermedad y no por accidente o violencia.

MUERTE VIOLENTA

DUE: muerte. [...] M. vIOLENTA. La causada con una agresión.

ODIO MORTAL

DUE: odio. [...] OdIO MORTAL. V. «ODIAR mortalmente»; odiar [...] ODIAR MORTALMENTE. «Odiar

a muerte». Odiar hasta el punto de desear la muerte de la persona odiada. PASTILLA DE JABÓN

$D U E$ : pastilla. [...] Pieza de jabón de tocador.

$D E A$ : pastilla [...] 4 Pieza [de jabón de tocador].

PONER A SALVO:

DUE: salvo, -a. [...] A SALVO. (I) («Estar; Poner»). Seguro o protegido contra cualquier peligro. PRESTAR ATENCIÓN

DUE: atención. («Conceder, Dedicar [...] Prestar [...] 1 Facultad de atender.

PIEL DE GALLINA

$D E A$ : piel $7 \sim$ de gallina. (reg) Carne de gallina.

RAMO DE FLORES

DUE: ramo. [...] 3 Manojo de flores, ramas, etc., que se arreglan de modo que forman un conjunto agradable: 'Un ramo de rosas'.

$D E A$ : ramo [...] 2 Conjunto [de flores, ramas o hierbas, esp. cortadas] dispuesto de modo que tengan sus tallos juntos.

REBANADA DE PAN

$D U E$ : rebanada. Porción delgada y de espesor uniforme cortada de una cosa en toda su anchura; particularmente, de un pan.

$D E A$ : rebanada $f$ Porción delgada [de algo, esp. de pan] cortada en toda su anchura. RISTRA DE AJOS

DUE: ristra. [...] «Sarta». Conjunto de ajos o cebollas sujetos uno a continuación de otro trenzando sus tallos u hojas.

$D E A$ : ristra $f 1$ Conjunto [de ajos o cebollas] que se forma trenzando los tallos. TABLETA DE CHOCOLATE

$D U E$ : tableta. 4 Placa de chocolate de las formadas por varias porciones, en que se vende ordinariamente; eran antes generalmente de media libra.

$D E A$ : tableta 1 Pieza rectangular, plana y poco gruesa [de un alimento sólido, esp. chocolate o turrón].

TOMAR APUNTES

DUE: apunte. [...] TOMAR APUNTES. Escribir lo que un profesor va explicando para poder estudiarlo después.

$D E A$ : apunte [...] 2 En pl: Datos de interés que se apuntan [1a] al oír una clase o una conferencia, al asistir a una reunión o al leer un libro. Frec con el $v$ TOMAR.

VIDA DE PERROS

DUE: vida. [...] V. PERRA [PERRA VIDA] o VIDA DE PERROS. «Vida arrastrada».

ZANJAR UNA DISCUSIÓN

DUE: discusión. («Encender, Suscitar; Empeñarse, Enredarse, Enzarzarse en; Entablar; Mantener, Sostener, Tener; Poner, Someter a; Cortar, Zanjar; acerca de, por, sobre»). Acción de discutir: 'El otro día sostuve una discusión con N. a propósito de eso'. 
B) Colocaciones documentadas en el lema correspondiente al colocativo ABOGADO DE OFICIO

$D E A$ : oficio [...] 9 de . [...] b) [Abogado] designado por turno para defender gratuitamente a un procesado que no ha nombrado defensor propio.

ASESTAR UN GOLPE

DUE: asestar. [...] 4 Hacer objeto a alguien de un golpe, puñalada, tiro, etc.

$D E A$ : $\operatorname{asestar}^{1} \operatorname{tr} 1$ Hacer que [alguien o algo (ci)] reciba [un golpe, un disparo o una herida $(c d)]$.

BARAJAR CITAS

DUE: barajar. [...] 4 Con «cifras, números, citas, datos» y nombres semejantes, emplearlos o manejar muchos en una exposición, una conferencia, etc.

BATALLA ENCARNIZADA

DUE: encarnizado, -a. [...] 1 Se aplica a «batalla, lucha, discusión», etc., cuando los contendientes ponen en ellas furia, ensañamiento o apasionamiento.

BATALLA FEROZ

$D E A$ : feroz adj 1 [...] d) [Cosa] que denota o implica gran agresividad o violencia. [...] Feroces batallas.

CARIÑO ENTRAÑABLE

$D U E$ : entrañable. (aplicado a «cariño» o nombre equivalente). Verdadero y profundo.

$D E A$ : entrañable [...] 1 Íntimo o profundo. Gralm referido a cariño o afecto. CERRAR UN TRATO

DUE: cerrar. [...] 17 «Ultimar». Terminar y dar por completamente establecido un trato: 'Aún no he cerrado trato [el trato] con el dueño de la casa'.

CLAVAR LA MIRADA

$D E A$ : clavar [...] 5 Fijar con insistencia [los ojos o la mirada]. COMIDA COPIOSA

$D U E$ : copioso, -a. Abundante; se aplica a nombres de conjunto de cosas menudas: 'Una copiosa nevada. Una copiosa cabellera'. O formado por muchas cosas provechosas o estimables: 'Un copioso botín. Una copiosa cosecha de cereales. Una comida copiosa'. COPIOSA NEVADA

DUE: copioso, -a. Abundante; se aplica a nombres de conjunto de cosas menudas: 'Una copiosa nevada. Una copiosa cabellera'. O formado por muchas cosas provechosas o estimables: 'Un copioso botín. Una copiosa cosecha de cereales. Una comida copiosa'.

CORRER UN RUMOR

DUE: correr. [...] 12 «Circular. Propagarse». Pasar de unos a otros una noticia, un rumor, etc. CUMPLIR LA LEY

DUE: cumplir. [...] 1 Realizar alguien aquello a que está obligado: «Acatar. Obedecer. Respetar». Hacer lo que determina una ley o disposición semejante.

$D E A$ : cumplir A 1 Hacer lo que determina [un precepto, una orden o un castigo]. [...] La ley puede ser ... Penal, si obliga bajo pena si no se cumple.

DECLARARSE UN INCENDIO

$D E A$ : declarar [...] 8 Comenzar a manifestarse [determinados fenómenos, esp. un incendio o enfermedad].

DESEAR FERVIENTEMENTE

$D U E$ : fervientemente. «Fervorosamente»: con fervor. [...] Con el verbo «desear» o equivalente, mucho, con mucha intensidad: 'Deseo fervientemente que ganes el premio'. DESPUNTAR EL DÍA

DUE: despuntar. [...] 2 «Apuntar». Asomar ligeramente algo que nace o aparece; particularmente, los brotes de las plantas, el día [el alba]. 
$D E A$ : despuntar [...] B intr 3 Comenzar a aparecer o manifestarse [algo, esp. el Sol o el día]. DIAMETRALMENTE OPUESTO

DUE: diametralmente. Con los adjetivos «opuesto, distinto» o equivalentes, «completamente»:

'Mi concepto de la vida es diametralmente opuesto al suyo'.

$D E A$ : diametralmente $a d v$. Completa o totalmente. Con el adj OPUESTO $u$ otro equivalente [...] Diametralmente opuesto [a Echegaray], el Padre Blanco García ... reconoce en Sellés cualidades poéticas, pero se muestra inflexible censor de la obra dramática.

DIENTE DE LECHE

$D E A$ : leche $[\ldots] 18$ de . [...] b) [Diente] de la primera dentición.

DINERO SUCIO

$D E A$ : sucio [...] 6 Innoble o vil. [...] c) [Dinero] que está fraudulentamente fuera del control fiscal.

DISCUSIÓN ENCARNIZADA

$D U E$ : encarnizado, -a. (adj.) 1 Se aplica a «batalla, lucha, discusión», etc., cuando los contendientes ponen en ellas furia, ensañamiento o apasionamiento.

DOLOR AGUDO

DUE: agudo, -a. [...] 5 (aplicado a sensaciones). «Vivo». Intenso y breve; particularmente, 'un dolor agudo'.

$D E A$ : agudo [...] 2 Intenso. Dicho normalmente de dolor y de otras sensaciones o sentimientos. ENCAPOTARSE EL CIELO

DUE: encaportarse. [...] 2 (aplicado al cielo, el día, el tiempo...). «Entoldarse. Nublarse».

Cubrirse de nubes, particularmente si son amenazadoras de tormenta.

$D E A$ : encapotarse [...] Cubrirse [el cielo] de nubes oscuras.

ENTABLAR UNA CONVERSACIÓN

$D E A$ : entablar [...] 1 Iniciar [una conversación, una relación o una lucha o disputa]. ENTABLAR UNA RELACIÓN

$D E A$ : entablar [...] 1 Iniciar [una conversación, una relación o una lucha o disputa]. ERROR CRASO

$D U E$ : craso, -a. [..] 2 (fig.; aplicado solamente a «error, ignorancia» o palabras equivalentes). «Burdo». Grosero.

$D E A$ : craso -sa [...] 2 (lit) [Error, o algo que lo implica] burdo o grosero. ERROR DE BULTO

DUE: bulto. [...] DE BULTO. (I) (aplicado a «error» o palabra equivalente). Muy perceptible o de importancia. ERROR GARRAFAL

$D E A$ : bulto [...] II loc adj 7 de . [Error] de evidente importancia.

DUE: garrafal. [...] 1 «Enorme. Mayúsculo». Muy grande, aplicado a cosas que no son materiales y que son malas o inconvenientes: 'Un error garrafal. Una mentira garrafal'.

$D E A$ : garrafal adj 1 Muy grande. Referido normalmente a cosas no materiales, esp errores o defectos.

ÉXITO CLAMOROSO

$D U E$ : clamoroso, -a. 1 Acompañado de clamor: 'Un recibimiento [Un éxito] clamoroso. Aplausos, vivas clamorosos'.

$D E A$ : clamoroso -sa [...] 3 Extraordinario o fuera de lo común. Con intención ponderativa. Esp referido a éxito o triunfo.

FE CIEGA

$D E A$ : ciego -ga [...] 5 [Cosa no material] que se da sin reflexión y sin reservas. [...] Solo me queda el recuerdo. Y fe ciega en la bondad de los hombres. 
FUMADOR EMPEDERNIDO

DUE: empedernido, -a. [...] 2 [...] «Incorregible». Se aplica como adjetivo a un nombre calificativo con que se designa a la persona que tiene el vicio o costumbre a que se refiere ese nombre tan arraigado que no se le puede quitar: 'Un jugador [bebedor, fumador, trasnochador] empedernido'.

$D E A$ : empedernido -da [...] 2 [Pers.] incorregible, o que tiene muy arraigado un vicio. [...] La intoxicación crónica se observa en individuos que por su profesión (empleados en garajes, cocineros, fumadores empedernidos) inhalan continuamente pequeñas dosis de ácido de carbono.

GUARDAR LA LEY

DUE: guardar. 16 Cumplir u obedecer; atenerse alguien en su conducta a la palabra dada, a sus promesas, a las leyes o preceptos, etc.

$D E A$ : guardar [...] 5 Cumplir u observar [una ley, un precepto o una obligación]. HAMBRE CANINA

$D E A$ : canino -na I adj [...] 2 [Hambre] muy fuerte.

HOMBRE DE BIEN

$D E A$ : bien ${ }^{2}$ [...] 5 de $\sim$. [Pers.] honrada. Normalmente siguiendo al $n$ HOMBRE. LIMPIEZA EN SECO

$D E A$ : seco -ca [...] II [...] 21 en . [...] b) Sin agua. Con el $v$ LIMPIAR. Tb adj, referido a limpieza. LOCAMENTE ENAMORADO

$D U E$ : locamente. «Con locura». Mucho o muy. (Expresión muy frec., «locamente enamorado.»)

$D E A$ : locamente $a d v$ De manera loca. [...] *Está locamente enamorada de él. LUJO ASIÁTICO

$D E A$ : asiático -ca [...] b) [Lujo] extremado.

MEDIDA DRÁSTICA

DUE: drástico, -a. [...] 2 [...] Quizás por influencia del inglés, se emplea modernamente esta palabra con el significado de «enérgico» o «radical»: 'El gobierno dictó medidas drásticas para atajar la revolución'.

$D E A$ : drástico -ca 1 Sumamente enérgico. Dicho esp de medida o remedio. MEMORIA DE ELEFANTE

$D E A$ : elefante -ta [...] II loc adj 5 de . (col) [Memoria] muy buena. MOMENTO CRUCIAL

DUE: crucial. [...] 2 (fig.). Se aplica a algo, particularmente a «momento», que es decisivo en la cosa de que se trata; por ejemplo, en la vida de una persona.

DEA: crucial adj Decisivo. Frec con intención ponderativa [...] En los momentos cruciales de la vida de Ignacio, mosén Francisco intervenía.

MUERTE NATURAL

$D E A$ : natural I [...] 3 Tal como se produce en la naturaleza, o sin elaboración o transformación especial $[\ldots]$ b) [Muerte] que se produce por enfermedad y no por accidente o violencia.

MUERTE VIOLENTA

$D E A$ : violento -ta [...] 3 Que va contra la tendencia o condición naturales [...] b) [Muerte] que se produce por accidente o por agresión. NARIZ AGUILEÑA

DUE: aguileño, -a. De águila o como de águila. [...] Se emplea corrientemente aplicado a la cara o a la nariz afiladas y también a la persona que tiene afilado el rostro.

$D E A$ : aguileño ${ }^{1}$-ña I $a d j .1$ [Nariz] afilada y corva que recuerda el pico del águila.

NEVAR COPIOSAMENTE

DUE: copiosamente. De manera copiosa: 'Nieva copiosamente'. 
OBSERVAR LA LEY

DUE: observar. [...] 3 «Acatar. Cumplir. Guardar. Obedecer». Hacer lo que manda una ley o un precepto.

$D E A$ : observar [...] 5 Practicar [una ley, un precepto o una costumbre]. ODIO MORTAL

$D E A$ : mortal [...] 3 [Odio u otro sentimiento similar] implacable.

PERDIDAMENTE ENAMORADO

$D U E$ : perdidamente. Se aplica usualmente sólo a «enamorado» con el significado de «muy» o «muy violentamente».

DEA: perdidamente [...] Total o completamente. Gralm referido al $v$ ENAMORAR. [...] El joven Harald andaba perdidamente enamorado de Gyda.

PRESTAR ATENCIÓN

DEA: prestar [...] 3 Dar o hacer. Con determinados ns, como ATENCIÓN, APOYO, AYUDA, AUXILIO, DECLARACIÓN, SERVICIO.

RELACIÓN ESTRECHA

$D U E$ : estrecho, -cha. 5 (fig.; aplicado a «amistad, dependencia, relación» o palabras semejantes). Muy íntimo.

$D E A$ : estrecho -cha [...] 3 [Relación, unión o colaboración] muy próxima. REPICAR LAS CAMPANAS

DUE: repicar. [...] 3 intr. Sonar o tocar insistentemente las campanas, particularmente con toque vivo que expresa alegría.

$D E A$ : $\operatorname{repicar}^{1}[\ldots]$ Tocar [una campana] produciendo un sonido vivo y gralm. alegre. RESCINDIR UN CONTRATO

$D U E$ : rescindir. «Anular». Dejar sin efecto un contrato u obligación, por decisión de una o de ambas partes.

$D E A$ : rescindir $\operatorname{tr}($ Der) Dejar sin efecto [un contrato u obligación]. RESCINDIR UNA OBLIGACIÓN

$D U E$ : rescindir. «Anular». Dejar sin efecto un contrato u obligación, por decisión de una o de ambas partes.

$D E A$ : rescindir $\operatorname{tr}(\mathrm{Der})$ Dejar sin efecto [un contrato u obligación]. ROGAR ENCARECIDAMENTE

$D E A$ : encarecidamente adv. De manera encarecida. [...] Rogamos encarecidamente a cuantos deseen participar en alguna de las secciones de dicha exposición se sirvan remitir cuanto antes el boletín correspondiente.

VIDA DE PERROS

$D E A$ : perro -rra [...] 20 de $\sim \mathbf{s .}$ (col) Muy malo o desagradable. Normalmente referido al tiempo, la vida o el humor.

ZANJAR UNA DISCUSIÓN

$D E A$ : zanjar $t r$ Resolver de manera expeditiva [una discusión o una dificultad].

\section{REFERENCIAS BIBLIOGRÁFICAS}

Aguilar-Amat Castillo, A. (1993): «En torno a la combinatoria del léxico: los conceptos de colocación e idiomatismo», en C. Martín Vide, ed., Lenguajes naturales y lenguajes formales. Actas del IX Congreso de lenguajes naturales y lenguajes formales, Barcelona, PPU, pp. 267-272. 
Alonso Ramos, M. (1994-1995): «Hacia una definición del concepto de colocación: de J. R. Firth a I. A. Mel'čuk», Revista de Lexicografía, I, pp. 9-28.

(2002): «Colocaciones y contorno de la definición lexicográfica», Lingüistica Española Actual, XXIV/1, pp. 63-96.

y B. SAnRomán Vilas (2000): «Construcción de una base de datos de colocaciones léxicas», Revista de la Sociedad Española de Procesamiento del Lenguaje Natural, 24, pp. 97-98.

Alvar Ezquerra, M. (2000): «Unidades fraseológicas definidas como de sentido o significado claro en el diccionario de María Moliner», en G. Corpas Pastor, ed., Las lenguas de Europa: Estudios de fraseología, fraseografia y traducción, Granada, Comares, pp. 231-248.

BALly, Ch. (1951 [1909]): Traité de stylistique française, Paris, Librairie Klincksieck.

Bargalló Escrivá, M., J. Caramés Díaz, V. Ferrando Aramo y J. A. Moreno Villanueva (19971998): «El tratamiento de los elementos lexicalizados en la lexicografía española monolingüe», Revista de Lexicografía, IV, pp. 49-65.

Bosque, I. (2001): «Sobre el concepto de ‘colocación’ y sus límites», Lingüística Española Actual, XXIII/1, pp. 9-40.

(2004): «Combinatoria y significación. Algunas reflexiones», en I. Bosque, dir., REDES. Diccionario combinatorio del español contemporáneo, Madrid, SM, pp. LXXVII-CLXXIV.

CALDERÓn CAmpos, M. (1994a): Sobre la elaboración de los diccionarios monolingües de producción, Granada, Universidad de Granada.

CALDERÓN CAMPOS, M. (1994b): «Sobre la elaboración de los diccionarios monolingües de producción: las definiciones, los ejemplos y las colocaciones léxicas», en P. J. Slagter, dir., Foro Hipánico, 6. Aproximaciones a cuestiones de adquisición y aprendizaje del español como lengua extranjera o lengua segunda, Amsterdam, Editions Rodoju, pp. 105-119.

Castillo Carballo, M. A. (1998): «El término colocación en la lingüística actual», Lingüística Española Actual, xx/1, pp. 41-54.

- (2000): «Tratamiento de las unidades pluriverbales en dos diccionarios del español: DRAE y DUE», en S. Ruhstaller y J. Prado Aragonés, eds., Tendencias en la investigación lexicográfica del español, Huelva, Universidad de Huelva, pp. 357-364.

- (2001a): «La fijación sintagmática en el diccionario», en E. Méndez, J. Mendoza y Y. Congosto, eds., Indagaciones sobre la lengua. Estudios de filología y lingüistica españolas en memoria de Emilio Alarcos, Sevilla, Universidad de Sevilla, pp. 395-416.

— (2001b): «Colocaciones léxicas y variación lingüística: implicaciones didácticas», Lingüística Española Actual, XXIII/1, pp. 108-133.

- (2001c): «Unidades fraseológicas y diccionarios: aplicaciones didácticas», en M. C. Ayala Castro, coord., Diccionarios y enseñanza, Alcalá de Henares, Universidad de Alcalá, pp. 151-161.

(2002): «Enunciados fraseológicos y enseñanza: algunas notas lexicográficas», en M. D. Fernández de la Torre Madueño, coord., Estudios sobre léxico. Análisis y docencia, Málaga, Universidad de Málaga, pp. 181-193.

Corpas Pastor, G. (1996): Manual de fraseología española, Madrid, Gredos. 
(1998): «Expresións fraseolóxicas e colocacións: clasificación», en X. Ferro Ruibal, coord., Actas do I Coloquio Galego de Fraseoloxía. Centro Ramón Piñeiro, Santiago de Compostela, 1997, Vigo, Xunta de Galicia, pp. 31-61.

(2001): «Apuntes para el estudio de la colocación», Lingüistica Española Actual, XXIII/1, pp. 4156.

COSERIU, E. (1977): «Las solidaridades léxicas», en Principios de semántica estructural, Madrid, Gredos, pp. 143-161.

DÉNIZ HERnÁnDEZ, M. (2000): «El tratamiento de las expresiones fijas en los diccionarios modernos del español», en S. Ruhstaller y J. Prado Aragonés, eds., Tendencias en la investigación lexicográfica del español, Huelva, Universidad de Huelva, pp. 377-386.

Ferrando Aramo, V. (2002): «Colocaciones y compuestos sintagmáticos: dos fenómenos léxicos colindantes», en A. Veiga, M. González Pereira y M. Souto Gómez, eds., Léxico y gramática, Lugo, TrisTram, pp. 99-107.

FIRTH, J. R. (1957): Papers in Linguistics 1934-1951, Londres, Oxford University Press.

García Godoy, M. T. (1994): «La enseñanza de las combinaciones léxicas asistida por ordenador», en P. J. Slagter, dir., Foro Hipánico, 6. Aproximaciones a cuestiones de adquisición y aprendizaje del español como lengua extranjera o lengua segunda, Amsterdam, Editions Rodoju, pp. 87-103.

Ginebra, J. (2002): «Las unidades del tipo dinero negro y dormir como un tronco: ¿naturaleza léxica o gramatical?», en A. Veiga, M. González Pereira y M. Souto Gómez, eds., Léxico y gramática, Lugo, TrisTram, pp. 147-154.

Hausmann, F. J. (1979): «Un dictionnaire des collocations est-il possible?», Travaux de linguistique et de littérature, 17/1, pp. 187-195.

(1998): «O diccionario de colocacións. Criterio de organización», en X. Ferro Ruibal, coord., Actas do I Coloquio Galego de Fraseoloxía. Centro Ramón Piñeiro, Santiago de Compostela, 1997, Vigo, Xunta de Galicia, pp. 63-81.

Higueras García, M. (2005): «Necesidad de un diccionario de colocaciones para aprendientes de ELE», en M. A. Castillo Carballo, O. Cruz Moya, J. M. García Platero y J. P. Mora Gutiérrez, eds., Las gramáticas y los diccionarios en la enseñanza del español como segunda lengua: deseo y realidad. Actas del XV Congreso Internacional de ASELE (Sevilla, 22-25 de septiembre de 2004), Sevilla, Universidad de Sevilla, pp. 480-490.

Írsula Peña, J. (1992): «Colocaciones sustantivo-verbo», en G. Wotjak, ed., Estudios de lexicología y metalexicografía del español actual, Tubinga, Max Niemeyer, pp. 159-167.

(1994): «¿Entre el verbo y el sustantivo quién rige a quién? El verbo en las colocaciones sustantivo-verbales», en A. Endruschat y otros, eds., Verbo e estructuras frásicas. Actas do IV Colóquio Internacional de Linguística Hispânica. Leipzig, 22-25 de Novembro de 1993, Porto, Facultade de Letras do Porto, pp. 277-286.

KoIKe, K. (2001): Colocaciones léxicas en el español actual: estudio formal y léxico-semántico, Alcalá de Henares, Universidad de Alcalá-Takushoku University.

Martínez Marín, J. (1991): «Fraseología y diccionarios modernos del español», Voz y Letra, II/I, pp. 117-126.

MeL'ČUK, I. A. (1993): «La phraséologie et son rôle dans l'enseignement/apprentissage d'une langue étrangère», Études de Linguistique Appliqué, 92, pp. 82-113. 
y A. K. ZolkovskiJ (1970): «Towards a Functioning Meaning-Text Model of Language», Linguistics, 57, pp. 10-47.

Olímpio de Oliveira Silva, M. E. (2007): Fraseografía teórica y práctica, Frankfurt am Main, Peter Lang.

Pamies Bertrán, A. y J. M. Pazos Bretaña (2003): «Acceso automatizado a fraseologismos y colocaciones en corpus no etiquetados», Language Design, 5, pp. 39-50.

Penadés Martínez, I. (2001): «¿Colocaciones o locuciones verbales?», Lingüistica Española Actual, $\mathrm{XXIII} / 1, \mathrm{pp} .57-88$.

_- (2004): «La enseñanza de la fraseología en el aula de E/LE», Carabela, 56, pp. 51-67.

— (2005): «Resultados y perspectivas de estudio en fraseología española», LynX. Panorámica de Estudios Lingüísticos, pp. 5-60.

Ruiz GuriLlo, L. (1997): Aspectos de fraseología teórica española, Valencia, Universitat de València. (2002): «Compuestos, colocaciones y locuciones: intento de delimitación», en A. Veiga, M. González Pereira y M. Souto Gómez, eds., Léxico y gramática, Lugo, TrisTram, pp. 327-339.

Ruiz MartínEZ, A. M. (2005): «El uso del diccionario en la enseñanza y aprendizaje de las colocaciones en español», en M. A. Castillo Carballo, O. Cruz Moya, J. M. García Platero y J. P. Mora Gutiérrez, eds., Las gramáticas y los diccionarios en la enseñanza del español como segunda lengua: deseo y realidad. Actas del XV Congreso Internacional de ASELE, Sevilla, Servicio de Publicaciones de la Universidad de Sevilla, pp. 785-791.

(2006): «El concepto de colocación en las páginas introductorias del DRAE», en A. Roldán Pérez, R. Escavy Zamora, E. Hernández Sánchez, J. M. Hernández Terrés y M. I. López Martínez, eds., Caminos actuales de la Historiografía Lingüística. Actas del V Congreso Internacional de la Sociedad Española de Historiografía Lingüística (Murcia, 7-11 de noviembre de 2005), Murcia, F. G. Graf, II, pp. 1409-1420.

Sinclair, J. M. (1991): Corpus, concordance, collocation, Oxford, Oxford University Press.

WотנAк, G. (1998): «Reflexiones acerca de construcciones verbo-nominales funcionales», en G. Wotjak, ed., Estudios de fraseología y fraseografia del español actual, Frankfurt-Madrid, Iberoamericana, pp. 257-279.

Zuluaga, A. (1980): Introducción al estudio de las expresiones fijas, Frankfurt-Bern-Cirencester, Peter D. Lang.

(1997): «Sobre fraseoloxismos e fenómenos colindantes», en X. Ferro Ruibal, coord., Actas do I Coloquio Galego de Fraseoloxía. Centro Ramón Piñeiro, Santiago de Compostela, 1997, Vigo, Xunta de Galicia, pp. 15-30.

(2002): «Los enlaces frecuentes de María Moliner. Observaciones sobre las llamadas colocaciones», Lingüística Española Actual, XXIv/1, pp. 97-114.

\section{DICCIONARIOS}

DPLE. A. C. Bolado, dir. (1990² [1988]): Diccionario práctico de la Lengua Española, Barcelona, Grijalbo.

REDES. I. BosQue, dir. (2004): REDES. Diccionario combinatorio del español contemporáneo, Madrid, SM. 
DAL. Diccionario Anaya de la Lengua, Madrid, Anaya, $1991^{3}$ [1979].

DESLE. Diccionario Esencial Santillana de la Lengua Española, Madrid, Santillana, 1991.

DL. Diccionario de la lengua, Madrid, Alianza Editorial, 1994.

CLAVE. C. Maldonado González, dir. (20025 [1997]): Clave. Diccionario de uso del español actual, Madrid, SM.

DSLE. J. Gutiérrez CuAdrado, dir. (1996): Diccionario Salamanca de la lengua española, Madrid, Santillana.

LEDLE. Larousse escolar. Diccionario de la lengua española, Barcelona, Larousse Planeta, 1993.

LJDCI. Larousse júnior. Diccionario ciclo inicial, Barcelona, Larousse Planeta, 1992.

DEM. A. MARTín (19816 [1960]): Diccionario del español moderno, Madrid, Aguilar.

DDEI. C. Maldonado GonzÁlez, dir. (1994³ [1993]): Diccionario didáctico de español intermedio, Madrid, SM.

DDEE. C. Maldonado GonzÁlez, dir. (1995² [1994]): Diccionario didáctico de español elemental, Madrid, SM.

DUE. M. Moliner (1966-1967): Diccionario de uso del español, Madrid, Gredos.

DiPELE. F. Moreno FernÁNDEZ, coord. (1995): Diccionario para la enseñanza de la lengua española, Barcelona-Alcalá de Henares, Biblograf-Universidad de Alcalá de Henares.

DRAE-1780. ReAl ACADEMIA Española (1780): Diccionario de la lengua castellana, Madrid, Joachin Ibarra.

DRAE-1817. Real ACADEMIa Española (18175): Diccionario de la lengua castellana, Madrid, Imprenta Real.

DRAE-1884. Real ACAdEMIA Española (1884'12): Diccionario de la lengua castellana, Madrid, Gregorio Hernando.

DRAE-1899. Real Academia Española (189913): Diccionario de la lengua castellana, Madrid, Hernando y Compañía.

DRAE-1914. Real Academia Española (1914 $\left.{ }^{14}\right)$ : Diccionario de la lengua castellana, Madrid, Sucesores de Hernando.

DRAE-1925. Real ACADEMIa Española (192515): Diccionario de la lengua española, Madrid, EspasaCalpe.

DMILE. Real Academia Española (19894): Diccionario Manual e Ilustrado de la Lengua Española, Madrid, Espasa-Calpe.

DRAE-1936-1939. Real Academia Española (1936-193916): Diccionario de la lengua española, Madrid, Espasa-Calpe.

DRAE-1947. Real ACAdemia Española (194717): Diccionario de la lengua española, Madrid, EspasaCalpe.

DRAE-1956. Real ACADEMIa Española (1956 $\left.{ }^{18}\right)$ : Diccionario de la lengua española, Madrid, EspasaCalpe.

DRAE-1970. Real ACADEMIa Española $\left(1970^{19}\right)$ : Diccionario de la lengua española, Madrid, EspasaCalpe. 
DRAE-1984. Real ACADEmia Española (198420): Diccionario de la lengua española, Madrid, EspasaCalpe.

DRAE-1992. Real ACADEMia Española (1992²1): Diccionario de la lengua española, Madrid, EspasaCalpe.

DRAE-2001. Real ACADEMIa Española (200122): Diccionario de la lengua española, Madrid, EspasaCalpe.

DBLE. A. SÁnchez PÉrez, dir. (19936 [1987]): Diccionario básico de la lengua española, Madrid, SGEL.

GDLE. A. SÁNChEz PÉREZ, dir. (19936 [1987]): Gran diccionario de la lengua española, Madrid, SGEL.

GDUEA. A. SÁNCHEz PÉrEz, dir. (2001): Gran diccionario de uso del español actual, Madrid, SGEL.

DEA. M. SeCO, O. ANDRÉS y G. RAmos (1999): Diccionario del español actual, Madrid, Aguilar.

DFDEA. M. SECO, dir. (2004): Diccionario fraseológico documentado del español actual, Madrid, Aguilar.

DFEM. F. VAREla y H. Kubarth (1994): Diccionario fraseológico del español moderno, Madrid, Gredos.

DEL. C. Villar RodríGuez, ed. (1999): Diccionario de la lengua española, Madrid, Espasa-Calpe. 